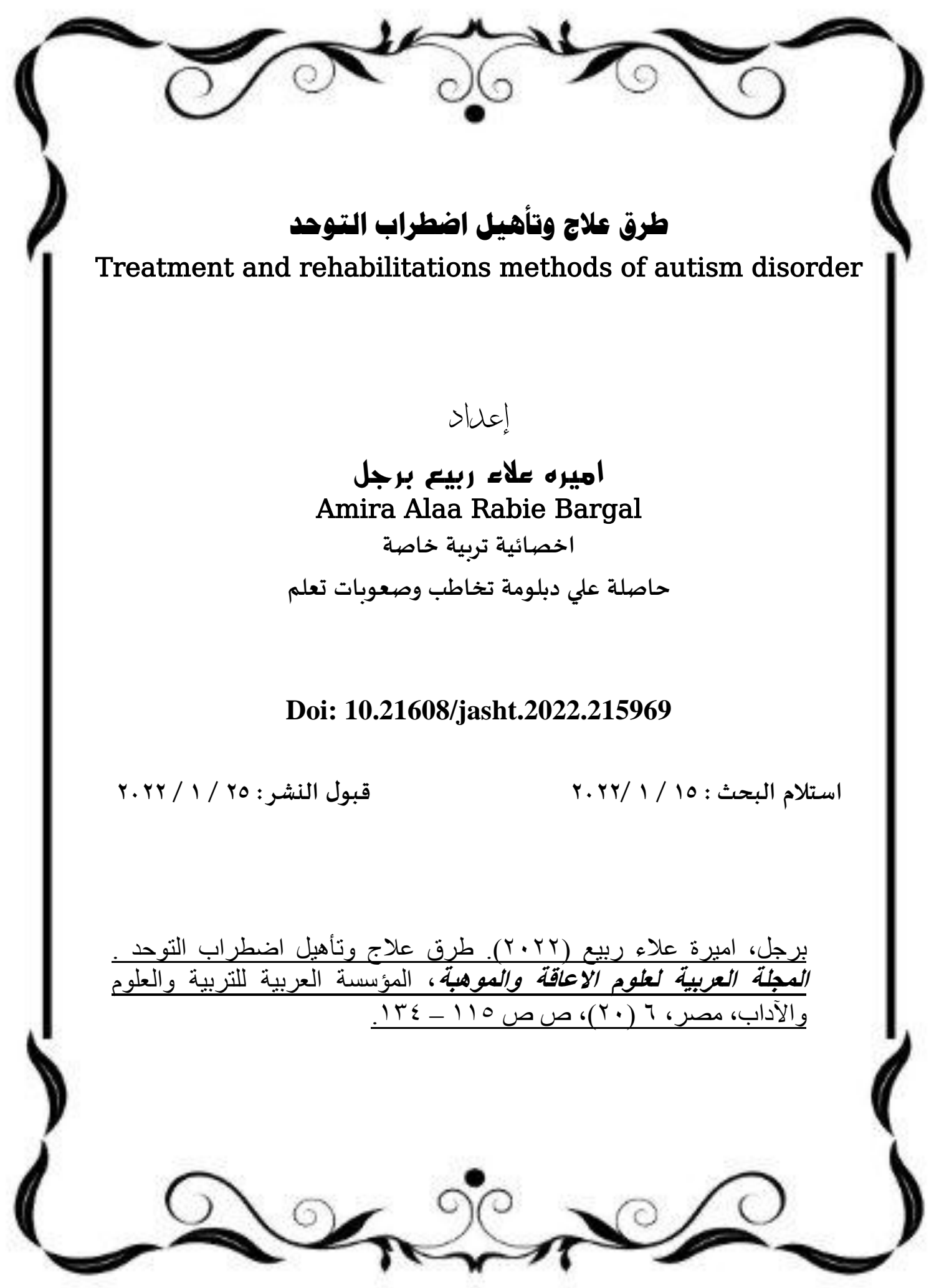




\section{طرق علاج وتأهيل اضطراب التوحد}

هدفت الدر اسة الحالية الى التعرف علي مفهوم اضطر اب التوحد وما يسبيه من قصور

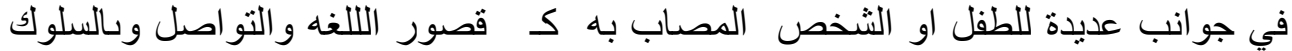

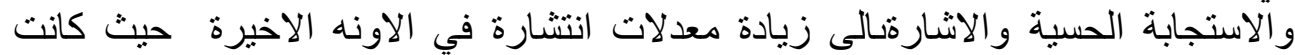

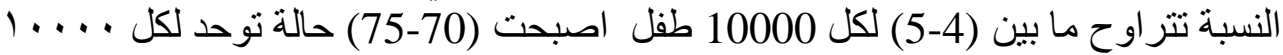

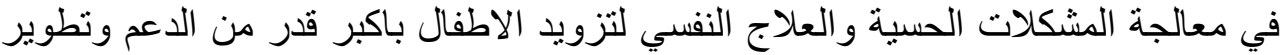

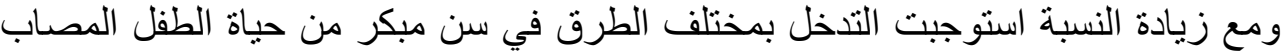

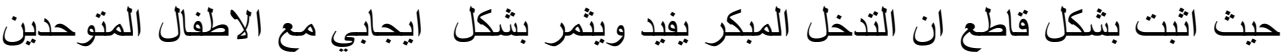

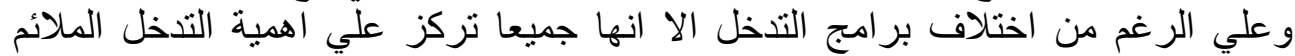

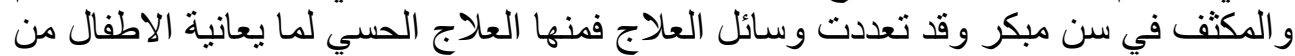

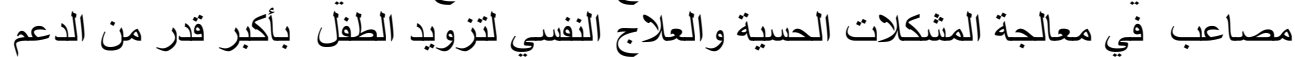

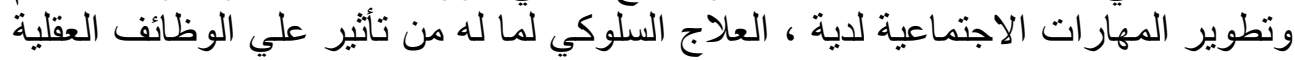

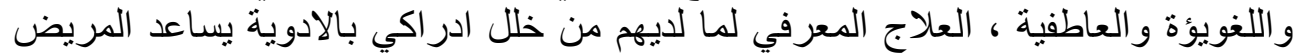

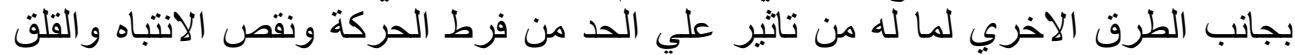

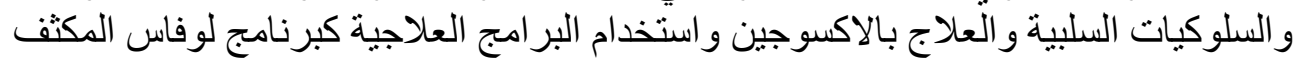

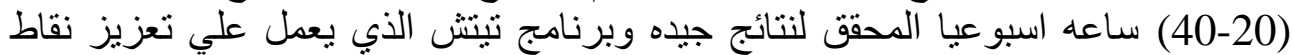

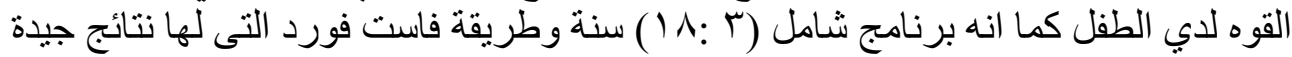

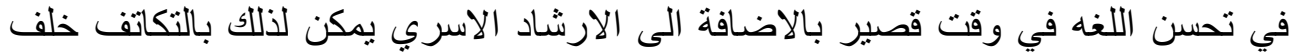

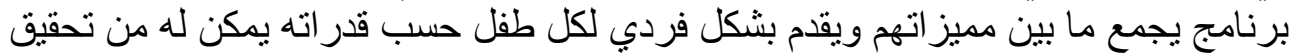
Abstract: الثفاء او التاهيل الذي يجعل منه شخص معتمد علي زئ زاته لئه مفيد لنفسه ولمجتمعه.

The current study aimed to identify the concept of autism disorder and what causes it to deficiencies in many aspects of the child or the person affected by it, such as lack of language, communication, behavior, sensory and signal response to the increase in its prevalence rates recently, where the ratio ranged between (5-4) per 10,000 children. (75-70) cases of autism per 10,000 in the treatment of sensory problems and psychotherapy to provide children with the greatest amount of support and development. With the increase in the percentage, it required intervention in various ways at an early age of the affected child's life, as it was conclusively proven 
that early intervention benefits and results in a positive way with autistic children. Despite the different intervention programs, they all focus on the importance of appropriate and intensive intervention at an early age. There are many means of treatment, including sensory treatment for the difficulties that children suffer in addressing sensory problems and psychotherapy to provide the child with the greatest amount of support and development of social skills, behavioral therapy for what It has an effect on mental, linguistic and emotional functions. Cognitive therapy because of their cognitive impairment with medicines helps the patient besides other methods because of its effect on the body. Reducing hyperactivity, attention deficit, anxiety, negative behaviors, oxygen therapy, and the use of treatment programs such as the intensive Lovas program (20-40) hours per week, which achieves good results, and the Teach program, which works to enhance the child's strengths, as it is a comprehensive program (3: 18) years and the Fastford method Which has good results in improving the language in a short time in addition to family counseling. This can be done by joining hands behind a program that combines their advantages and is presented individually to each child according to his abilities, enabling him to achieve recovery or rehabilitation that makes him a dependent person useful for himself and his community

التوحد اعاقة عرفت حديثا في وطننا العربي وهناك الكثير مما لم يسمعو ا بمشاكل

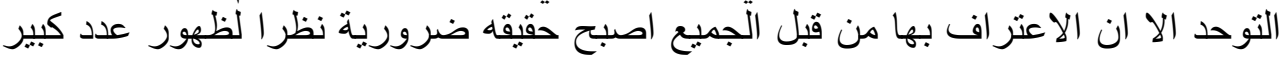

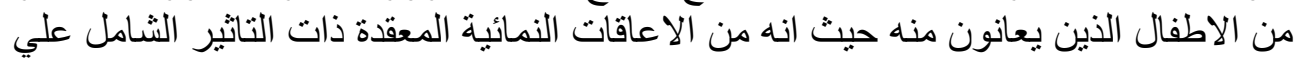

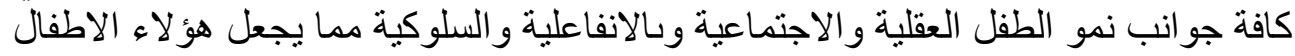

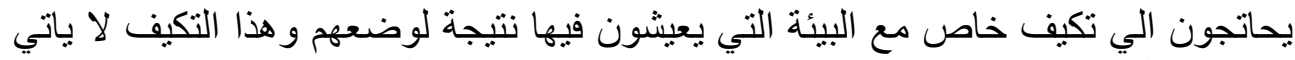

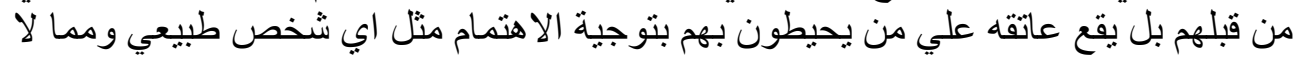

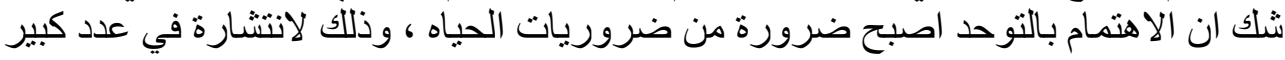

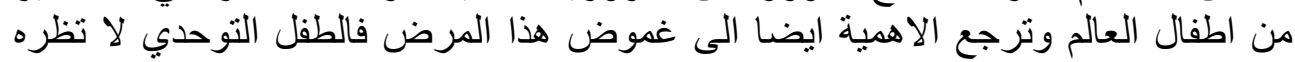


علية علامات الاعاقه كغيرة من الاطفال لانه يتسم بالمظهر الخارجي العادي مما استدعي

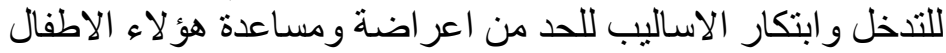

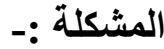

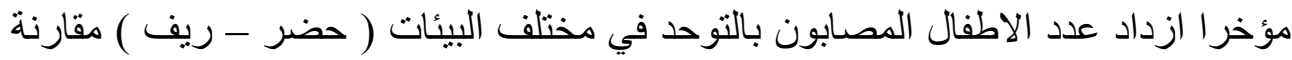

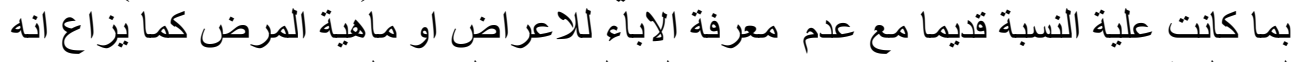

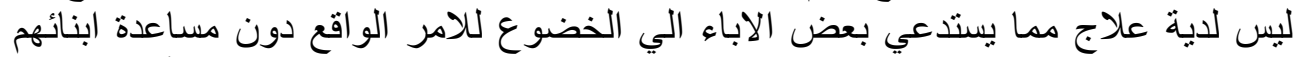

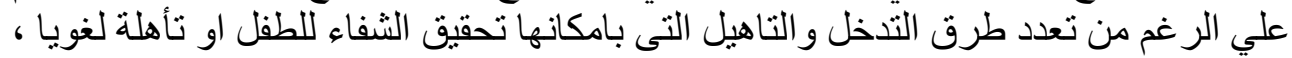

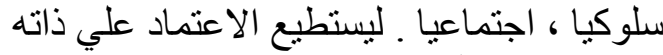
الهداف الدراسة : الجناعيا

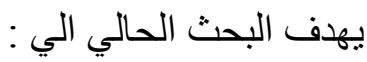

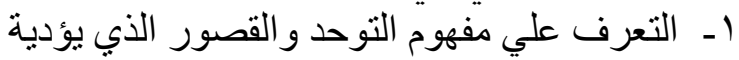

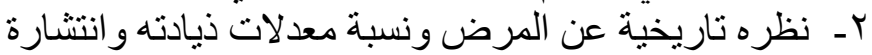

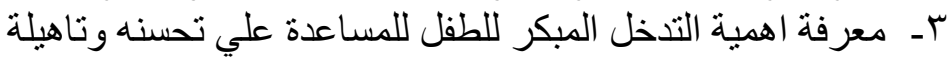

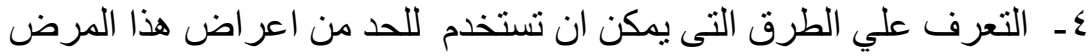

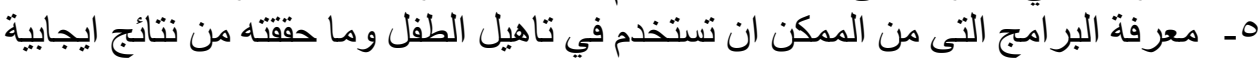

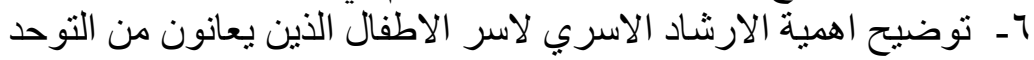

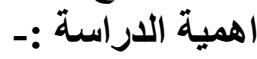
من خلال اطلاع الباحثة علي بعض الدارلة اسات السابقة في مجال التدخل لعلاجح وتأهيل

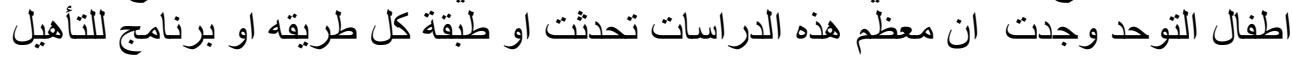

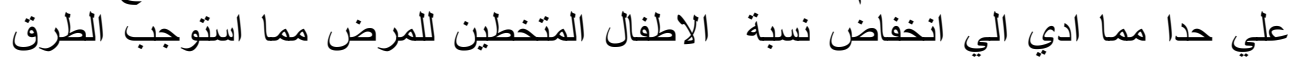

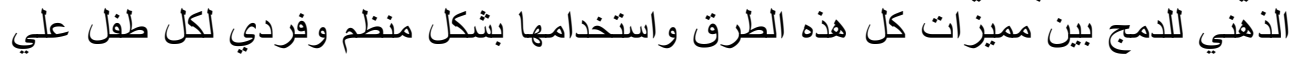

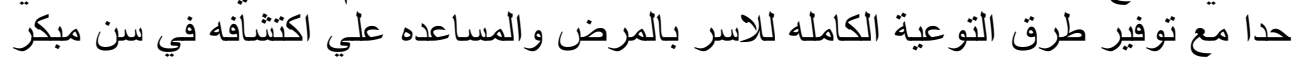

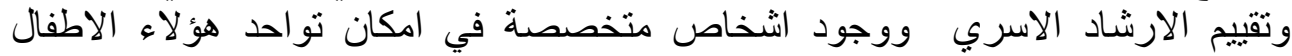

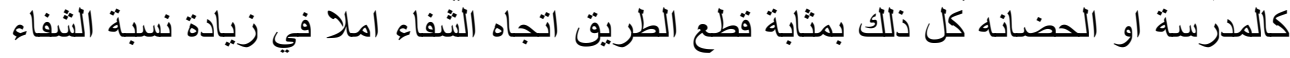

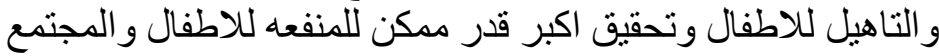

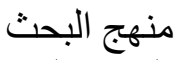
المنهج الوصفي لعرض مفهوم ونسبه التوحد وطرق التدخل والإرشاد الاسري لاسر الاطفال المصنابون بالتوحد.

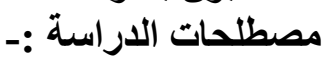

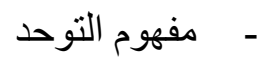

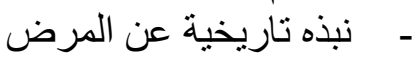

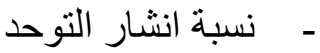




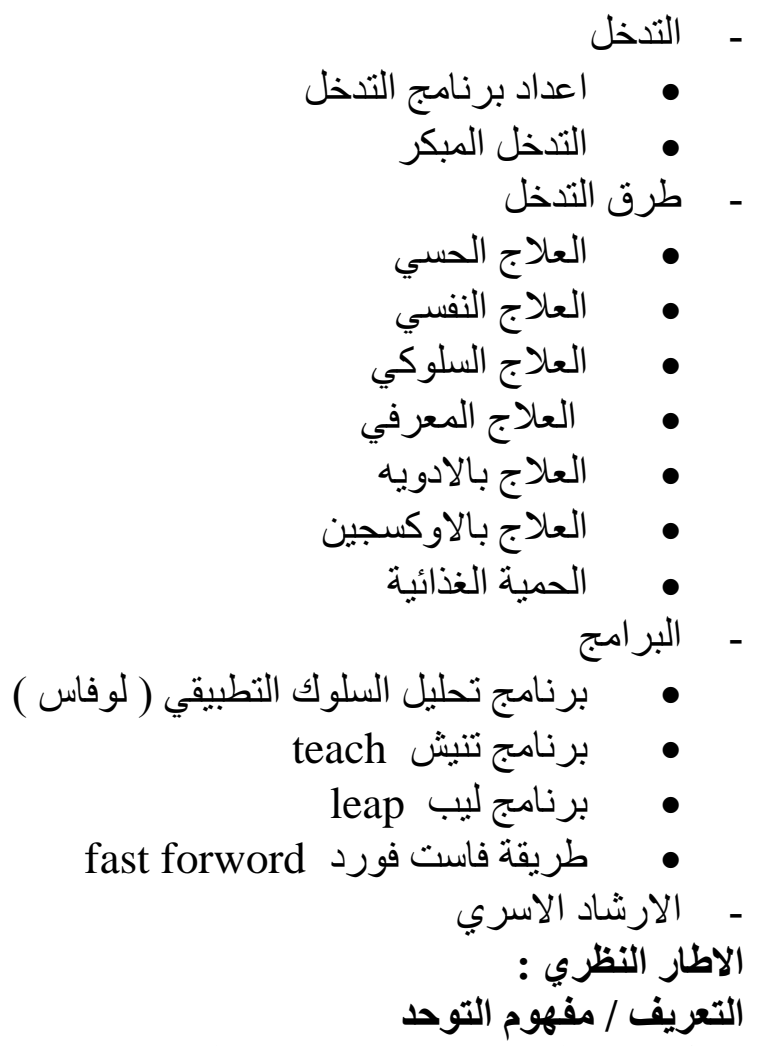

اصل كامة التوحد Autism و هي كلمة اغريقية وتنقسم الى نصفين الاولي

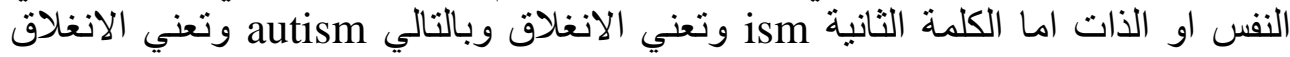

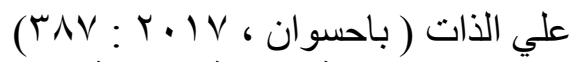
علي حسب منظمة الصحة العالمية

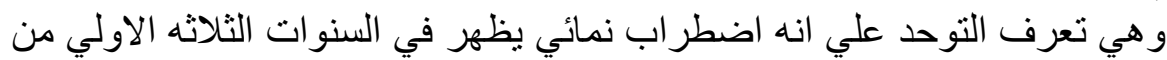

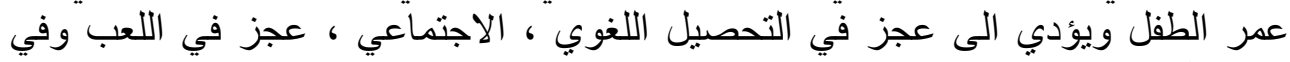

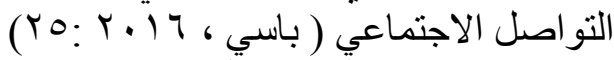

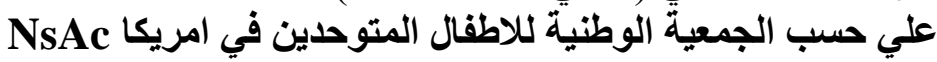

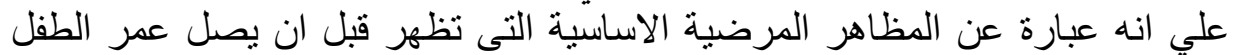

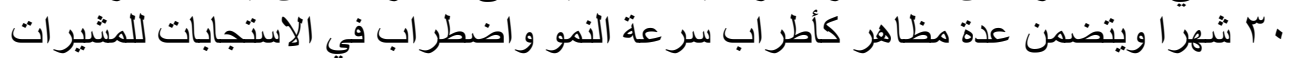

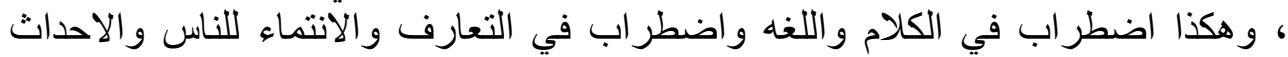

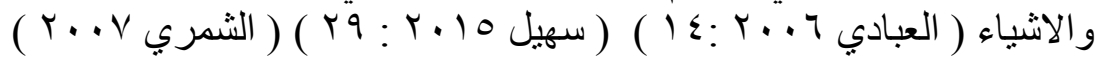




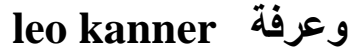

المختص بالطب النفسي للاطفال والذي يعتبر اول عالم اهتم بمظاهر التوحد عند الاطفال

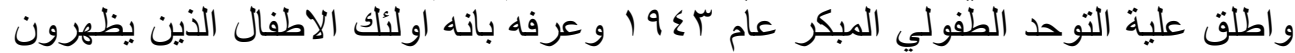
اضطر ابا في المظاهر الاتية :-

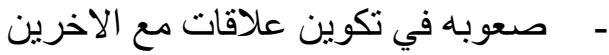

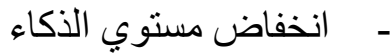

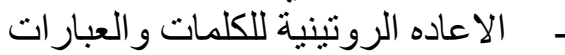

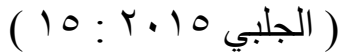

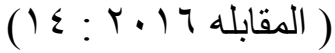

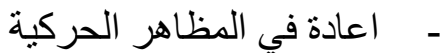

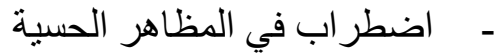

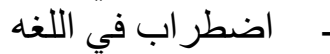

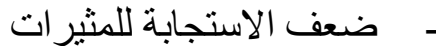

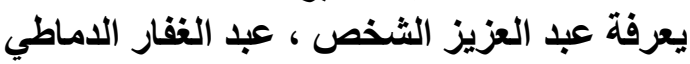

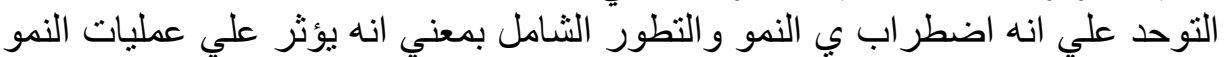

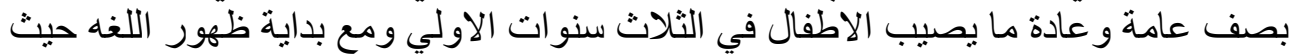

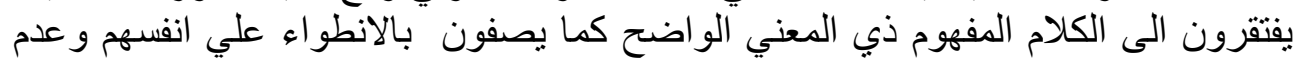

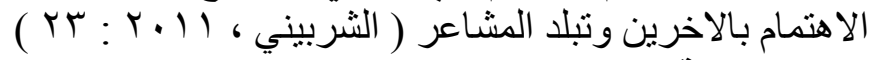
نظرة تاريخية حول التوحد

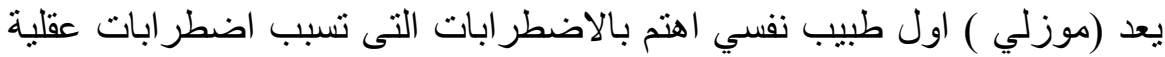

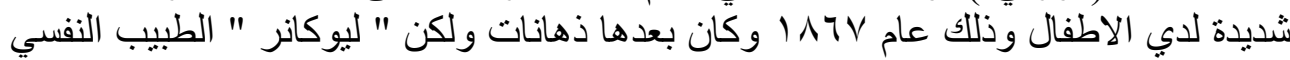

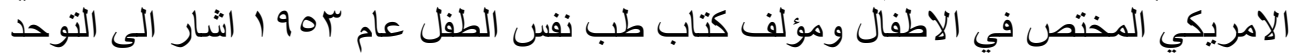

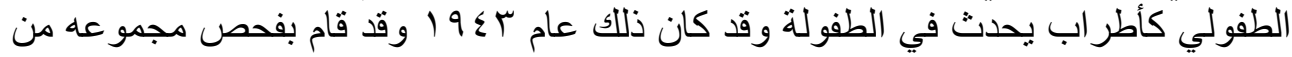

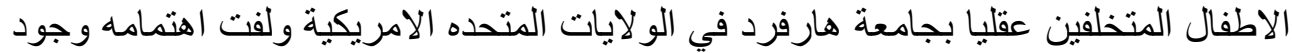

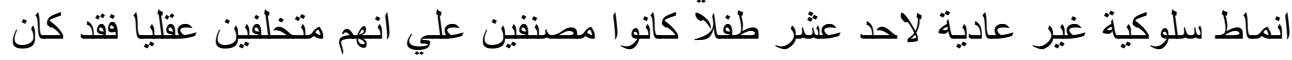

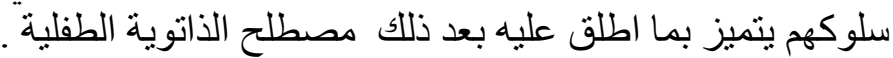
Early infantile autism

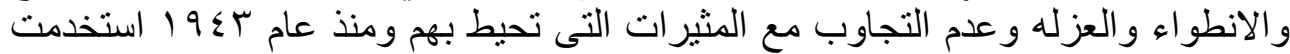

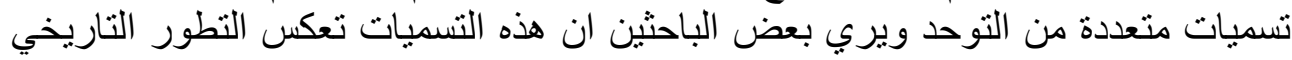

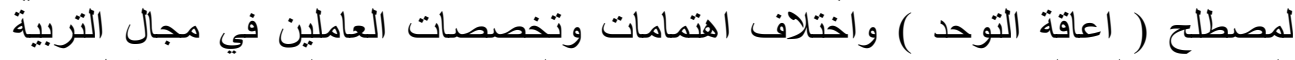

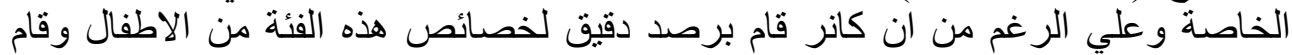

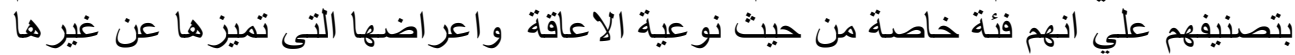

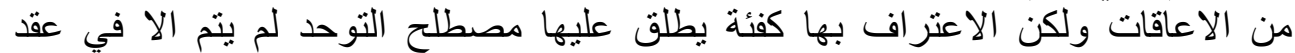

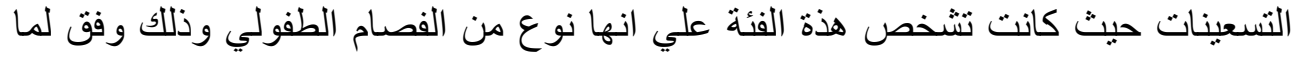




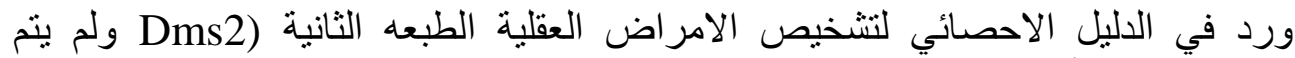

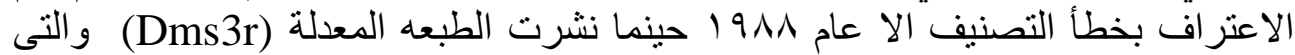

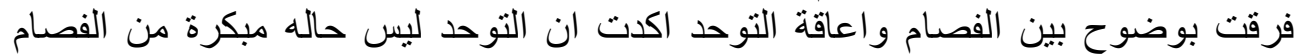

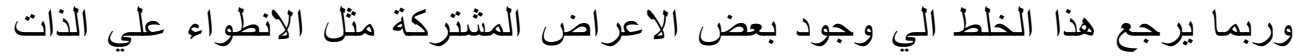

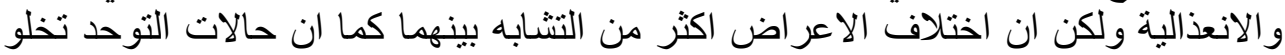

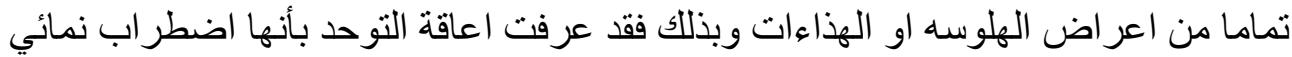

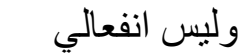
قدر جلبيرج

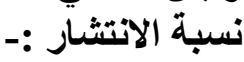

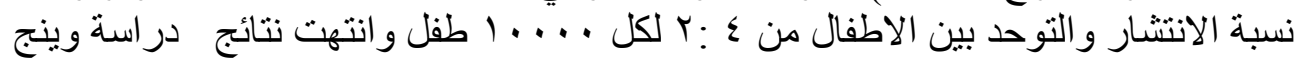

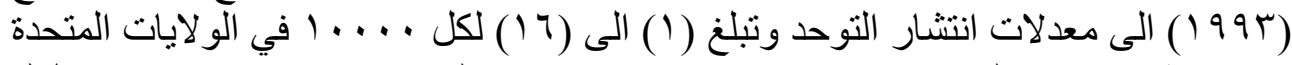

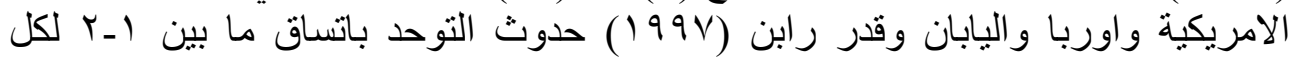

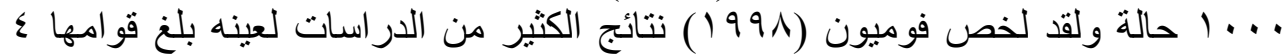

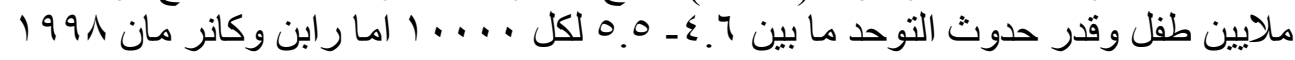

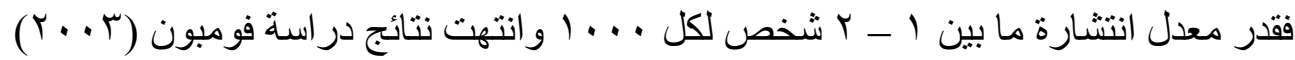

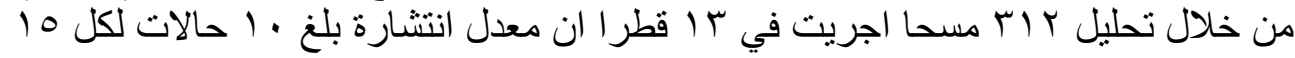

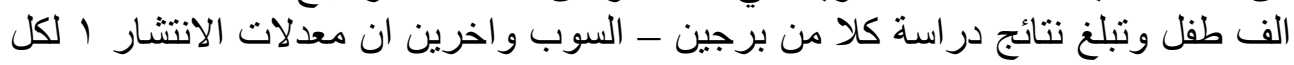

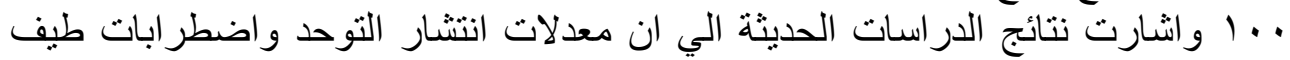

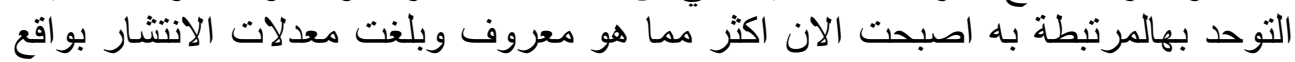

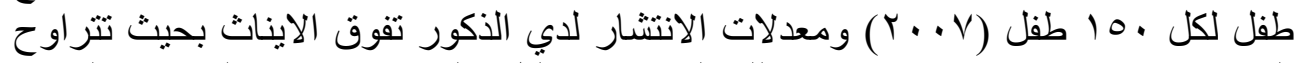

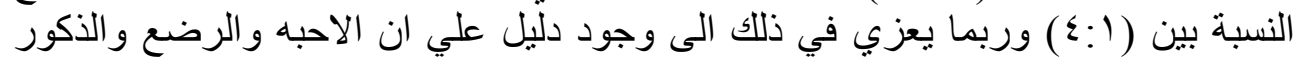

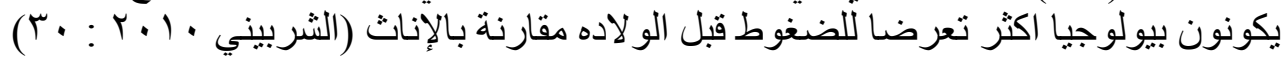

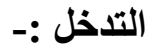
اولا اعداد برنامج التخل

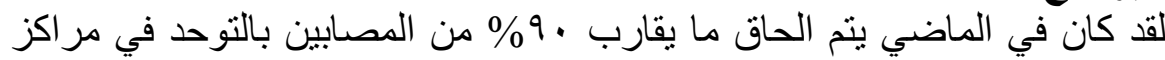

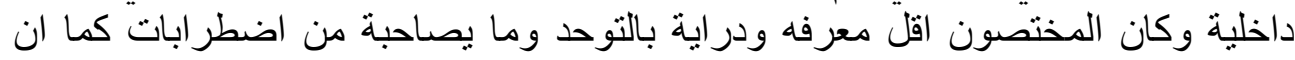

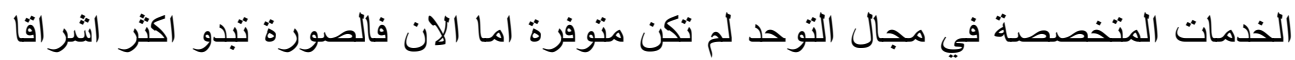

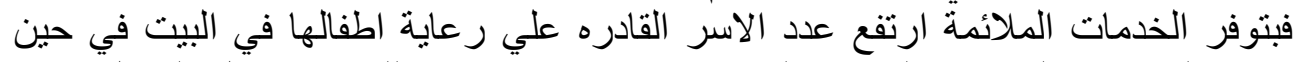

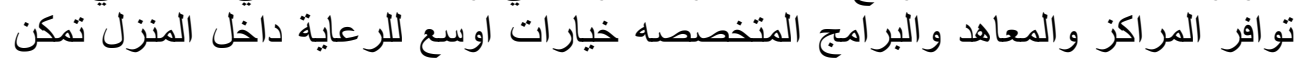

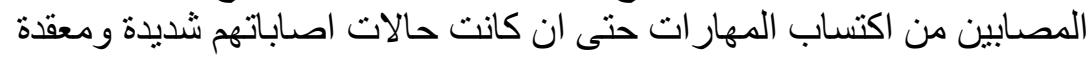

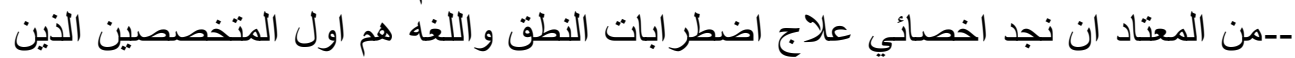

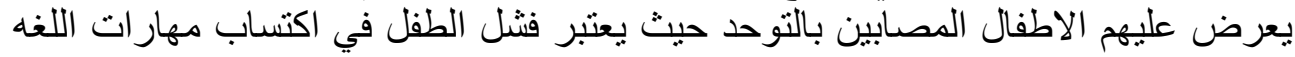




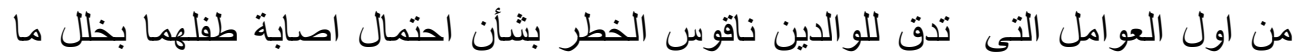

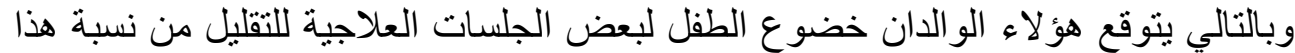

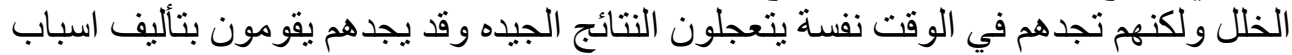

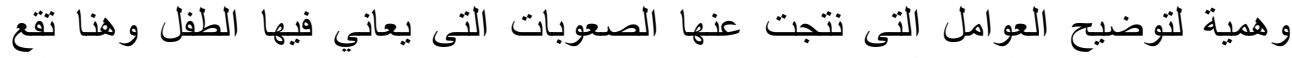

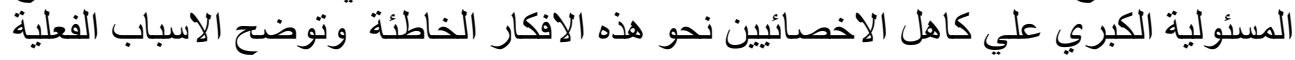

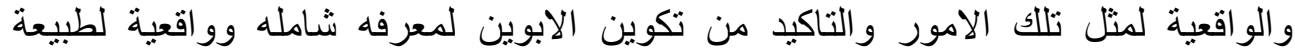

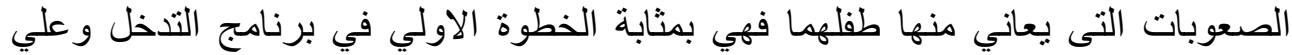

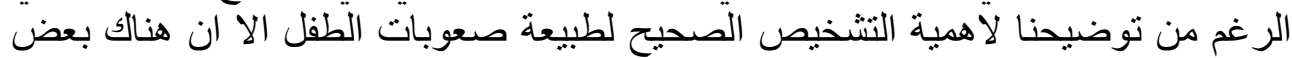

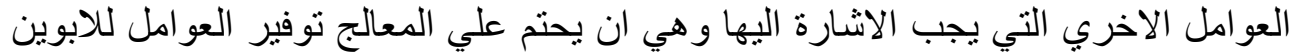

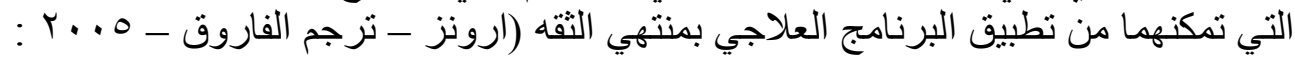

\section{التدخل المبكر}

ولقد اثبت بشكل قاطع ان التدخل المبكر يفيد ويثمر بشكل ايجابي مع الاطفال المتوحدين

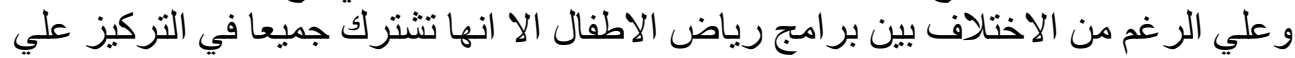

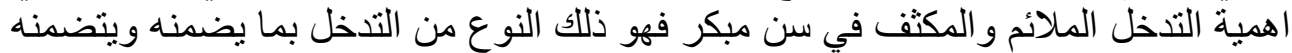

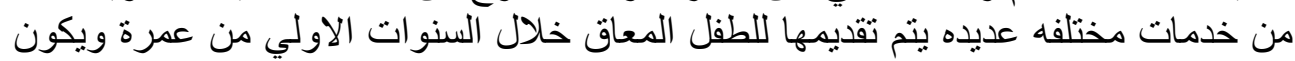

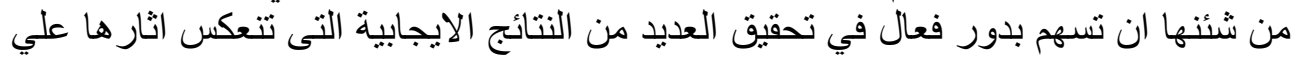

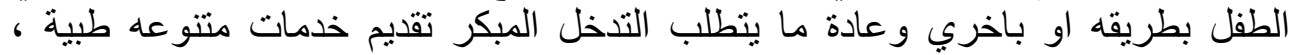

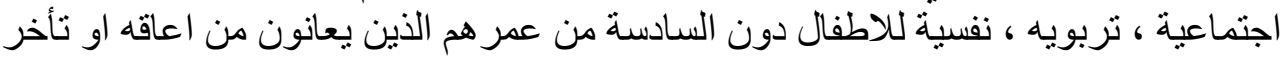

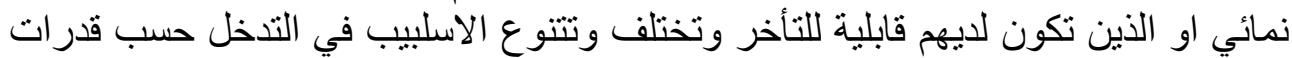

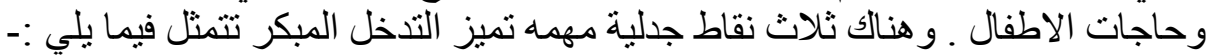

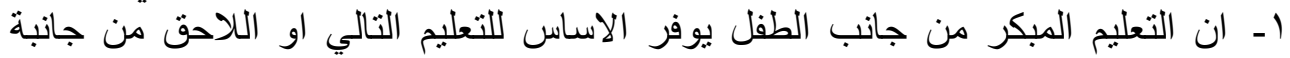

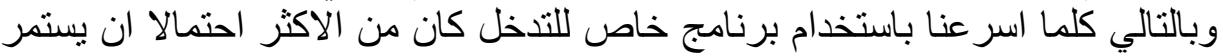

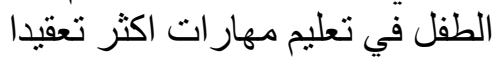

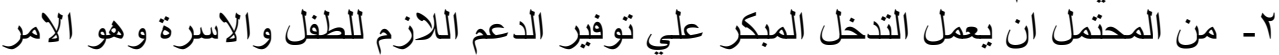

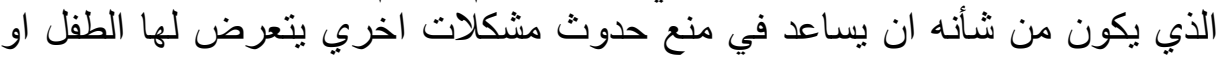

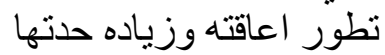

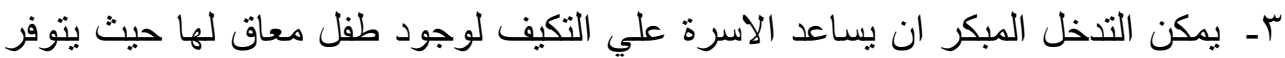

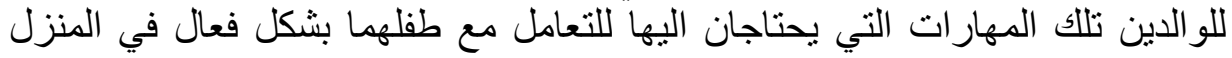

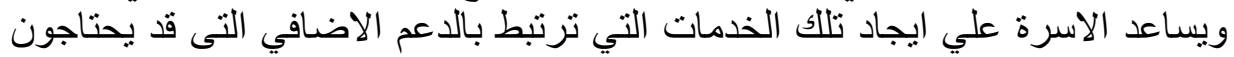
اليها مثل الارشاد او المساعدة الطبية او المالية تلإن 
ومن هذا المنطلق ينبغي ان يعمل العديد من المتخصصين معا بشكل جماعي حتي يتم

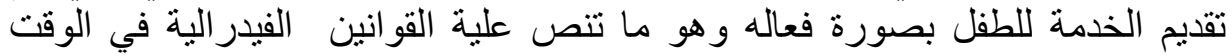

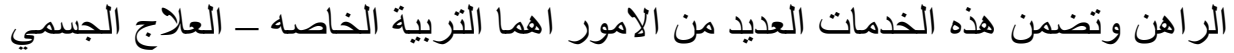

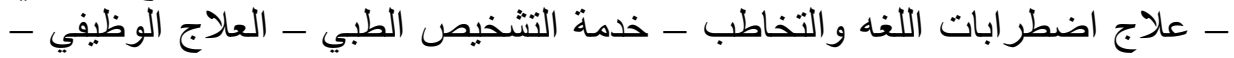

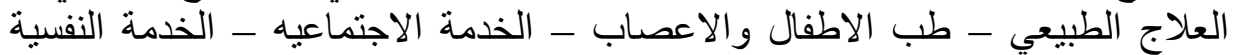

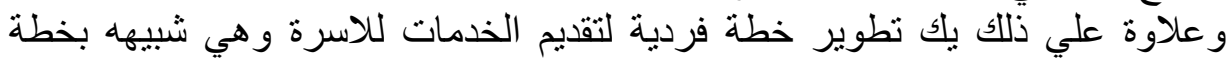

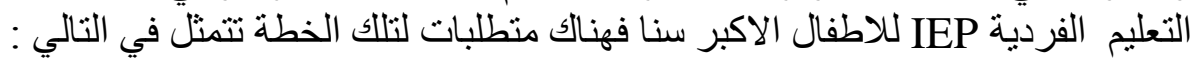

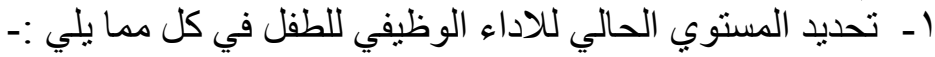

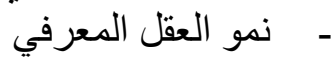

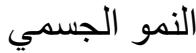

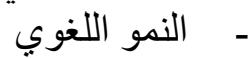

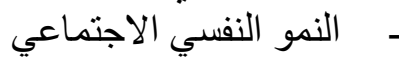
مساعدة الذات

r- تحديد تلك المصادر التى يمكن ان تستعين بها الاسرة واولوياتها واهتمامتها فيما

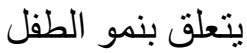
r- تحديد النتائج الاساسية المتوقعه بالنسبة لكل من الطفل وبالاسرة التى تضمن

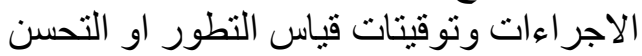

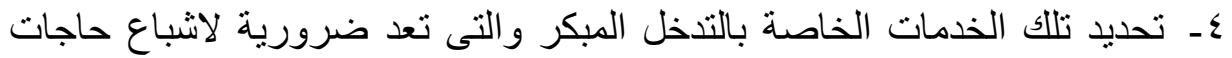

الطفل ـــ ـ المو اعيد المحدده لبداية ونهاية تقديم الخدمات

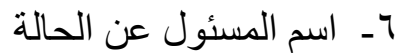
V- تحديد الخطوات المطلوبه لحدوث انتقال سلس من برنامج التدخل المبكر الي

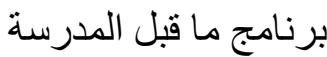

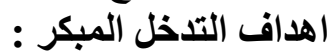
عند تقييم او اختيار برنامج معين للتنخل المبكر لابد من انلاعي الهدف الذي نود تحقيقه من خلاله 1ـ اكتساب الطفل مهارة معينه وتنميتها وتطوير ها او تتمية وتطوير مستوي هذه المهارة

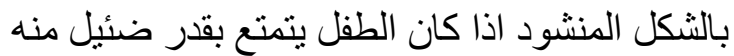

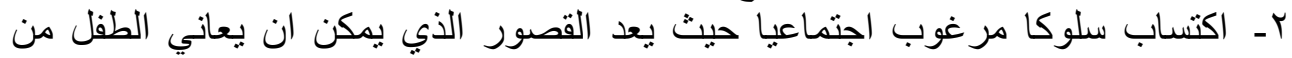

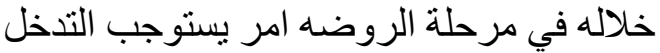

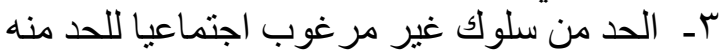
عـ التركيز علي جوانب القوه لدية 


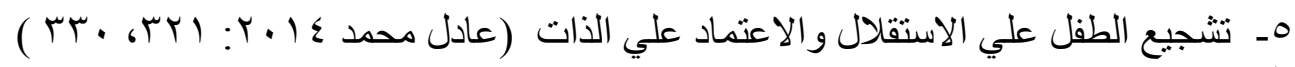
طرق التدخل :

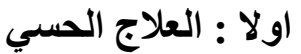
ان الاطفال المنوحدين يظهرون مصاعب الإن في معالجة المشكلات الحسية تظهر لايهم حساسية

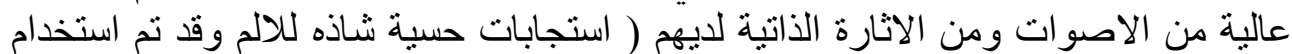

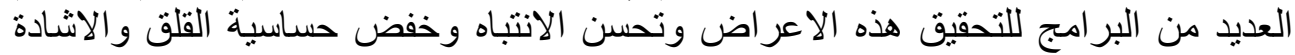

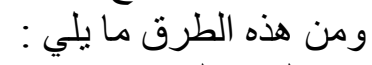

$$
\text { - }
$$

ثانيا : العلاج النفسي

كان علاج اعاقة التوحد باستخدام جلسات التحليل النفسي هو الاسلوب السائد حتي الإني

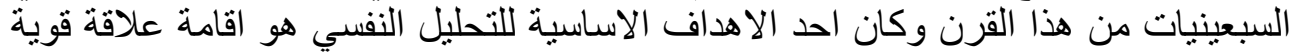

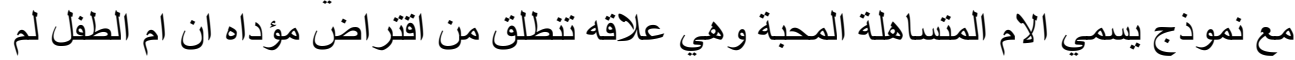

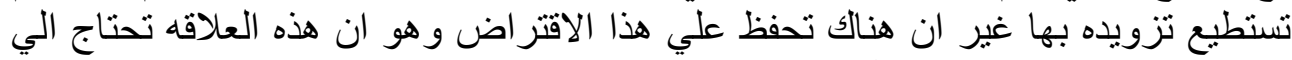

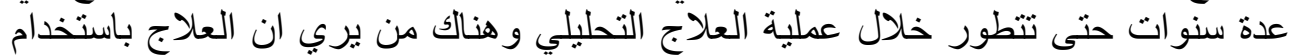

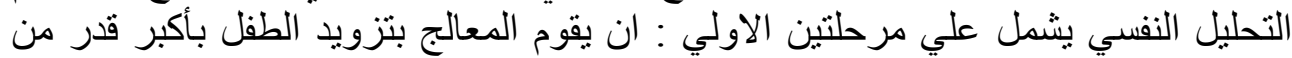

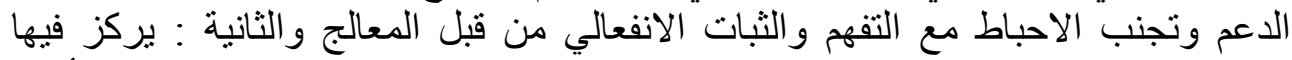

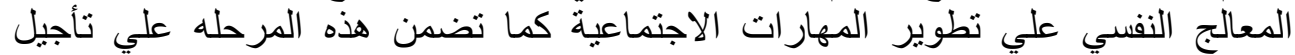

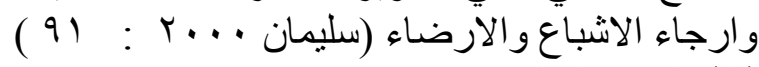
ثالثا العلاج السلوكي تعد طريقة تعديل السلوك من انسب الطرق العلاجية المعتمده علي نظرية العلاج

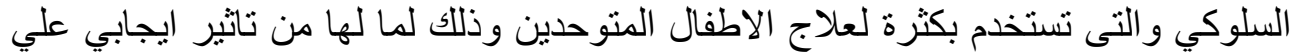

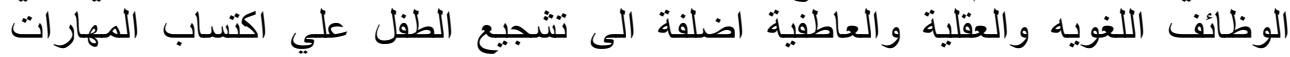

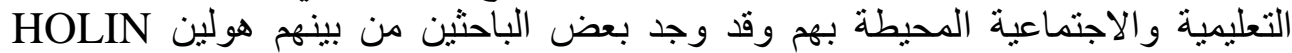

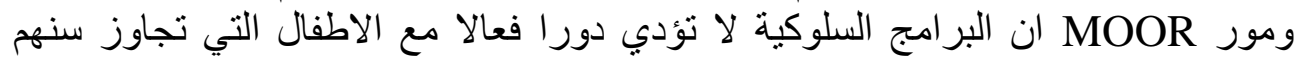

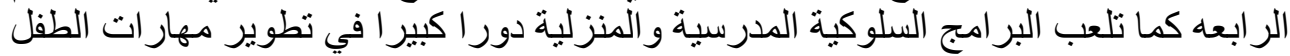

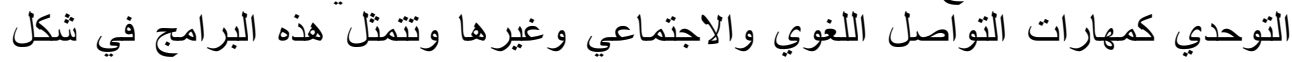

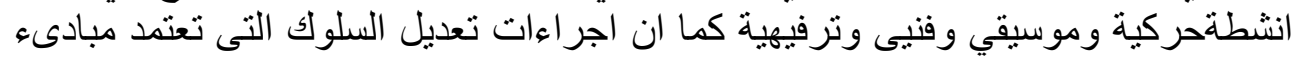

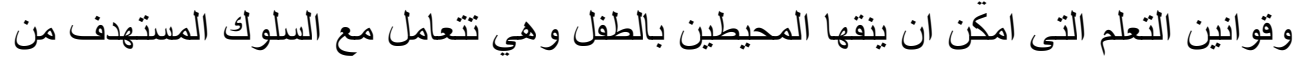


خلال زيادة السلوك اذا كان مرغوب فية او التقليل منه اذا كان غير مرغوب فئ فية او تشكيل

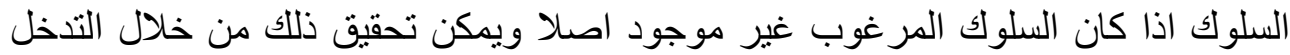

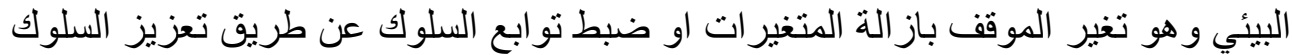

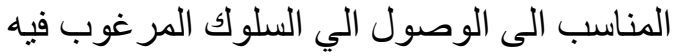

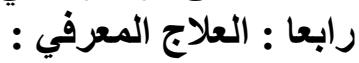

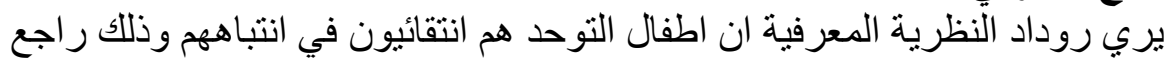

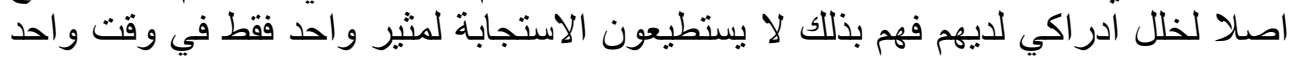

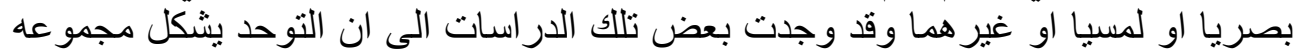

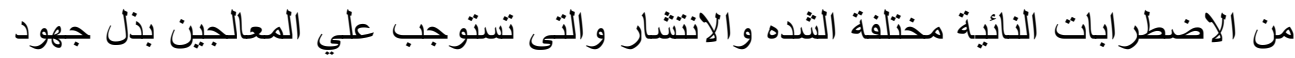

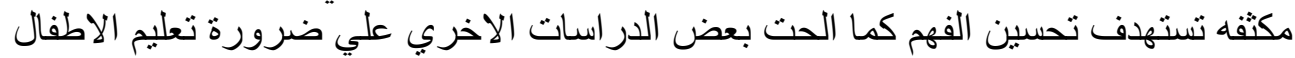

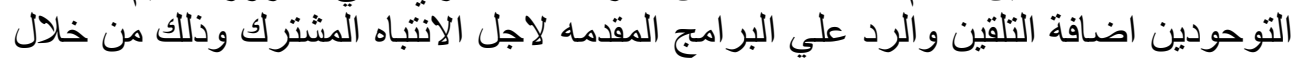

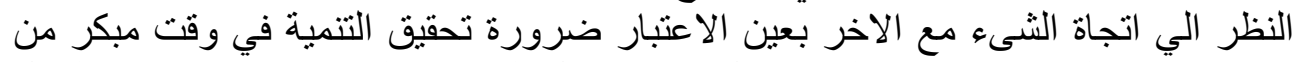

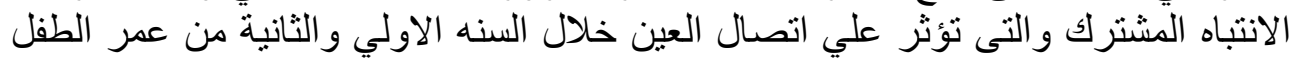

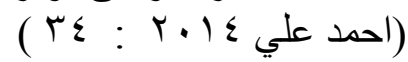

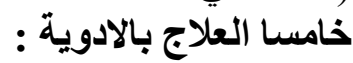

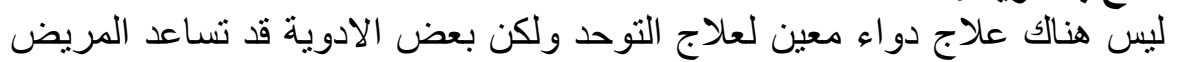

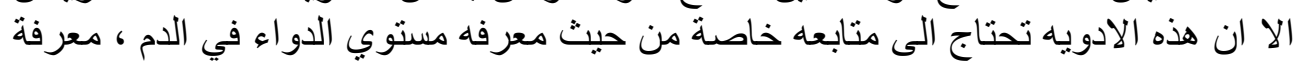

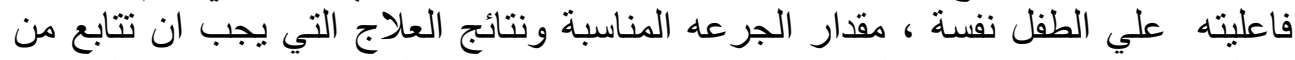

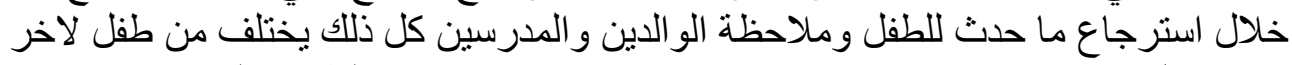

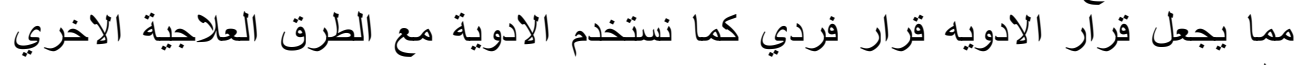

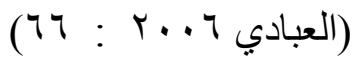
كما يوجد عدد من الادوية لها تاثير فعال في علاج سلوك الطفل الذي يعاني من التوحد ومن

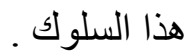

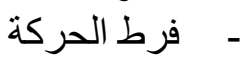
- - - - - - - - - - - - مقص القدرة علي الانتباه و التركيز -

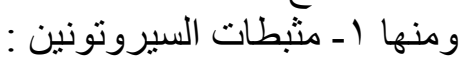
اكتشف الباحثون ارتفاع معدلات السيروتونين (SEROTONIN) في مجري الأني الدام حوالي ثلث حالات التوحد وباستخدام هذه العقاقير التي تعادل الاعر اضن اض ومنها : 
FLUVOXAMINE LUVOX

FLUOXETINE

PROZAC

لوحظ بعد تطبيق العلاج بهذه الادويه استجابة الطفل من :

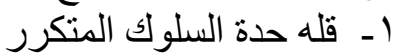

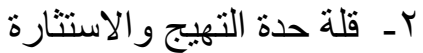

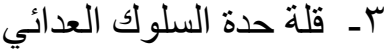

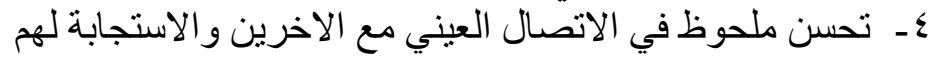

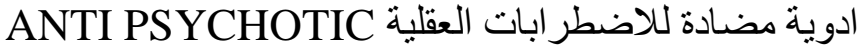

و هذه الادوية هي في الاصل لعلاج الانفصام الثخصي وتقلتل من :

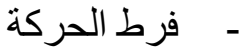

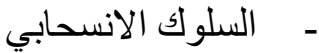

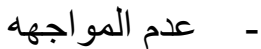
وقد اعتمدت اربعة عقاقير منها :

CLOZARIL/CLOZAPINE RISPERDUL/RISPERIDONE

ZYPREXA/OLANZAPINE

SEROQULE/QUELIAPINE ولكن من المحتمل ان يكون لها اثار جانبية ادوية محفزة من الكتية

وهي تستخدم بشكل اساسي للاطفال الذين يعانون من نقص الانتباه وفرط الحركة :

RITALIN ADDERALL

DEXEDINE العلاج بالاكسجين :

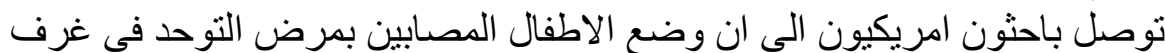

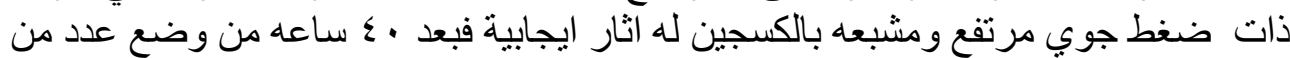

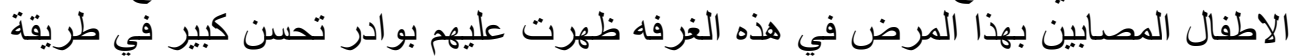

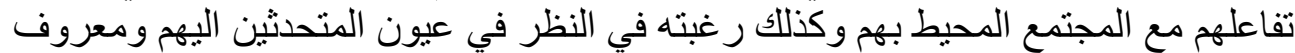

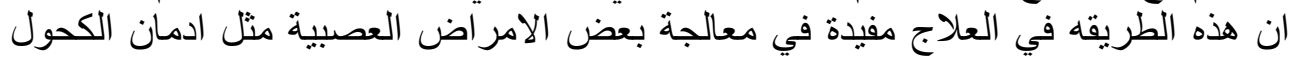

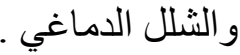




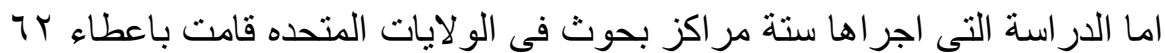

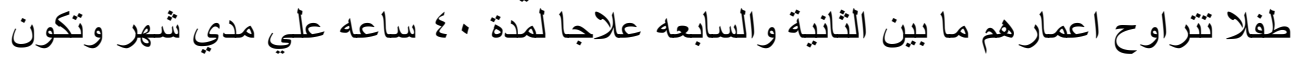

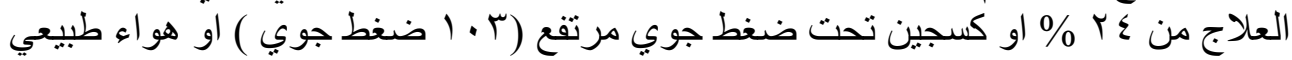

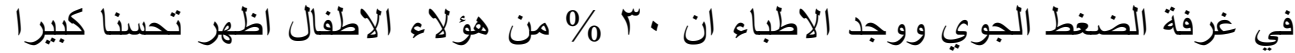

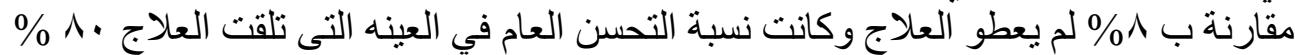

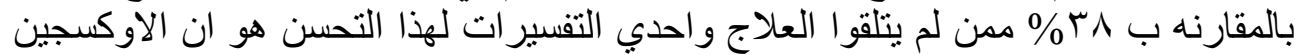

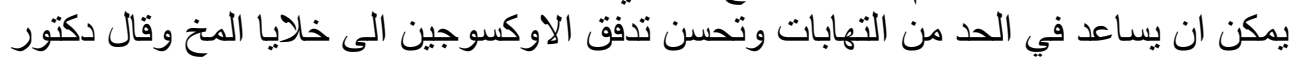

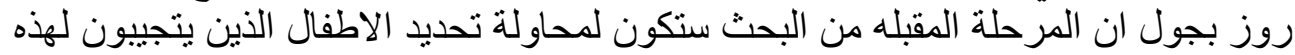

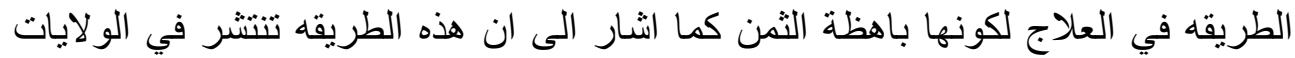

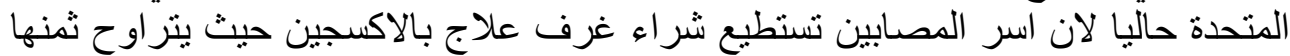

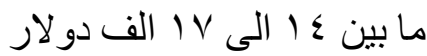

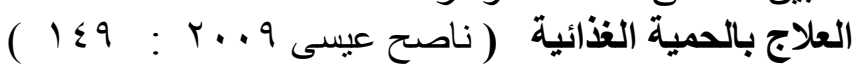
حيث يري اصحاب هذه النظرية ان اعراض اضل التوحد ناتجه عن التحليا غير السليم لبروتينات

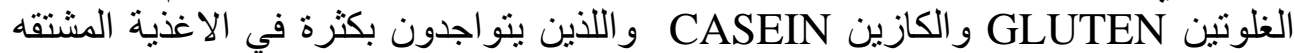

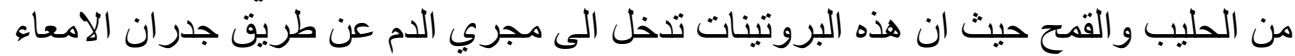

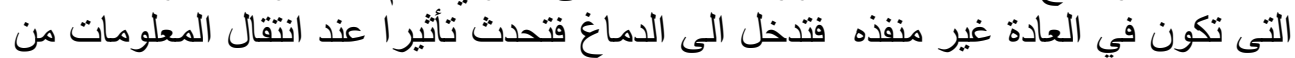

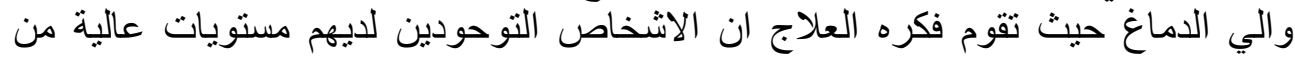
Beta endorphin

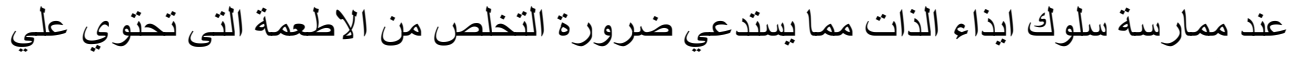
هذه البروتينات

\section{Anti yeust مضادات الخمائر الأنات}

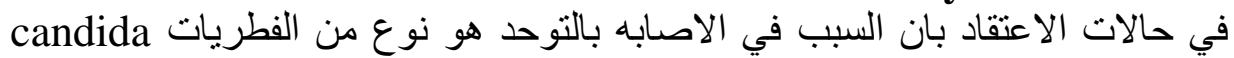

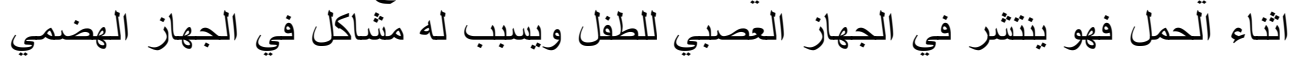

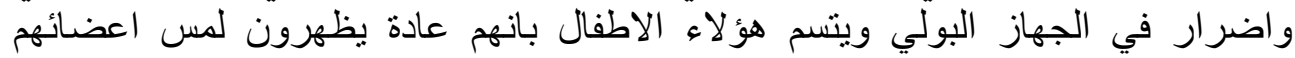

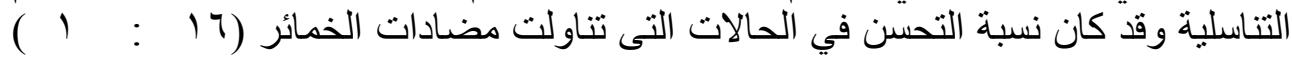

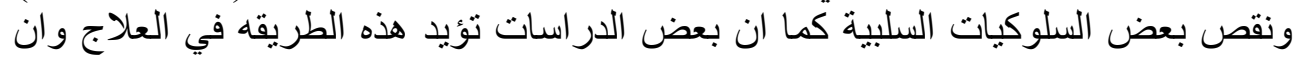

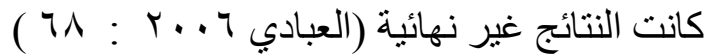

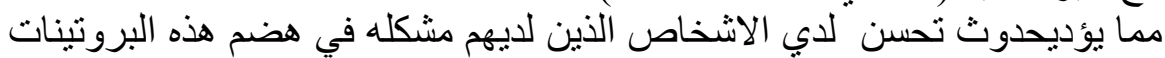

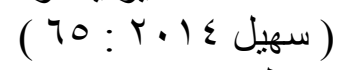

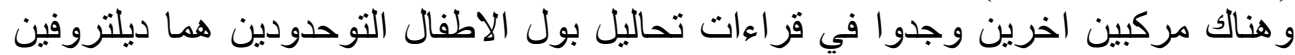

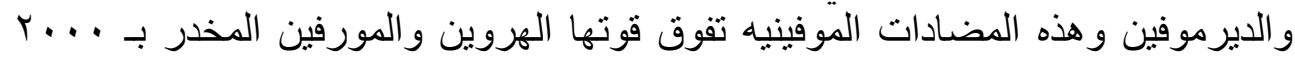


حيث ان هذه المواد المخدرة اما انها تسبب التوحد او تزيد من اعر اض التواء التوحد وقد يتساءل

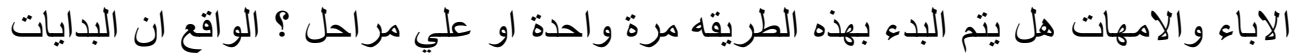

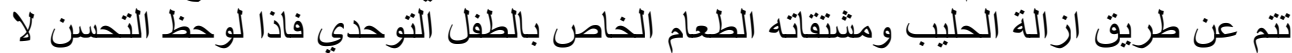

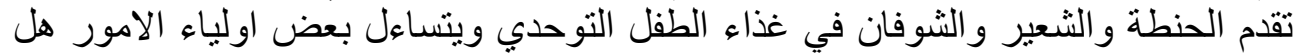

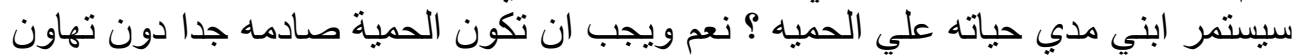

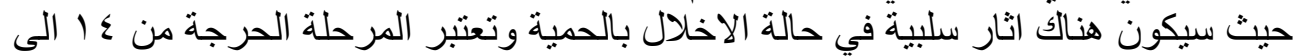

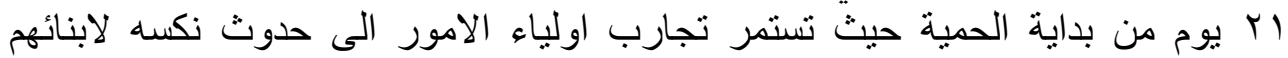

$$
\text { - } \text { - } \text { - }
$$

ويعزو الباحثون حدوث هذه النكسه الى انقطاع مادة البيتد الافيوني عن الجسم وتعتبر هذه ولانه

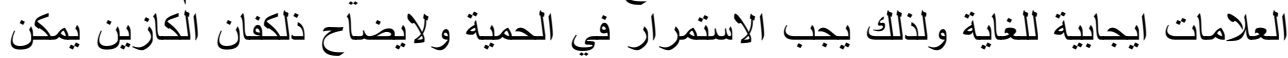

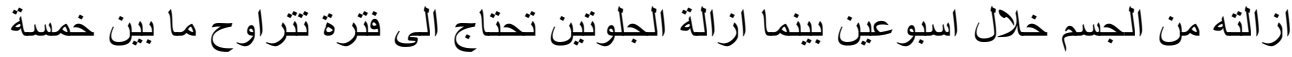

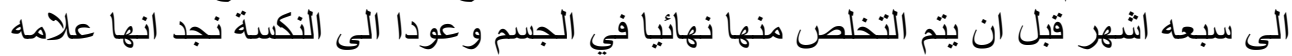

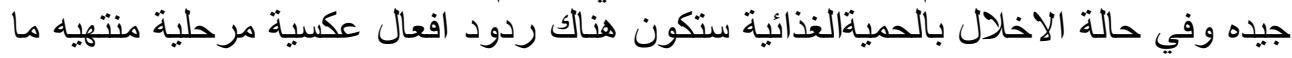

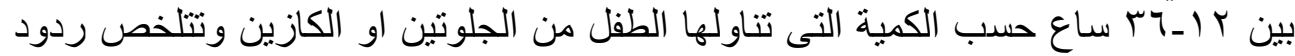

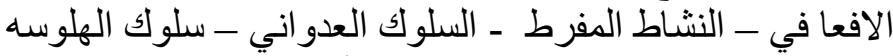

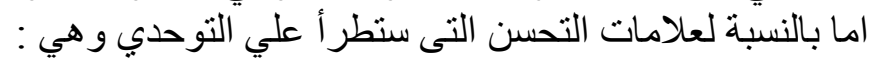

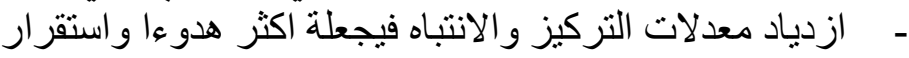

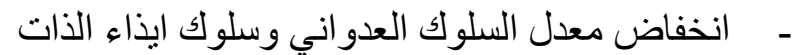
- - تحسن في الاتصالات الثفية التهية وغير الثفهيه

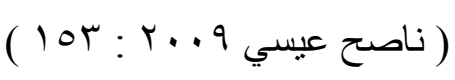

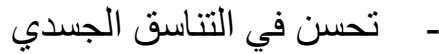

$$
\begin{aligned}
& \text { - م - تحسن في عادات الطعام }
\end{aligned}
$$

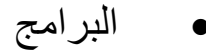

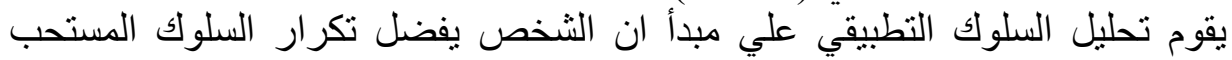

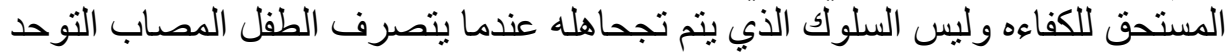
بالثكل الملائم مثل البده في التو اصل مع شخص اخر حتى لو كان ذلك في شكل لمحها 
ابره فيجب مكافاتة علي امل ان يقوم بتكرار هذا السلوك حتي يصبح السلوك في نهاية

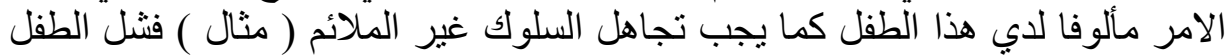

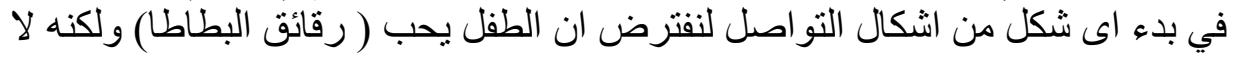

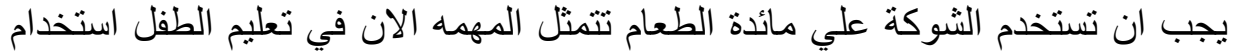

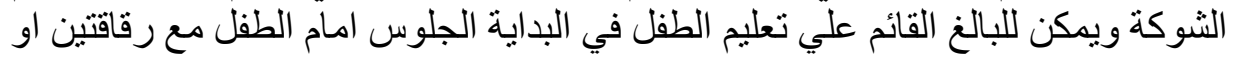

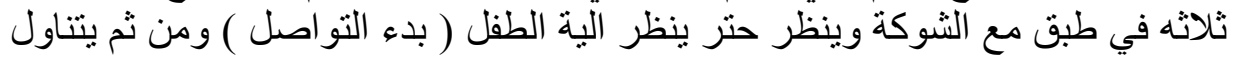

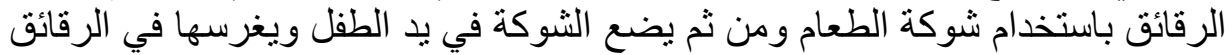

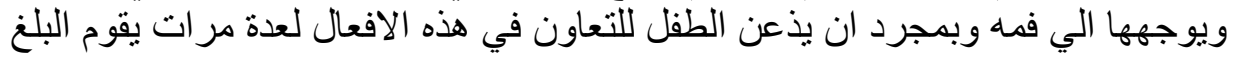

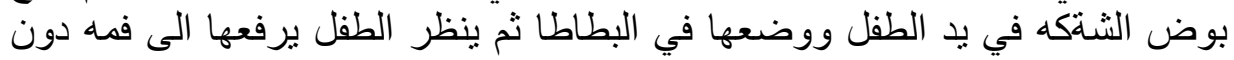

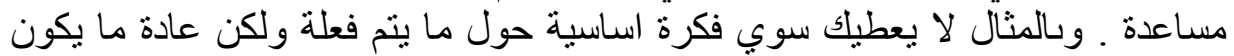

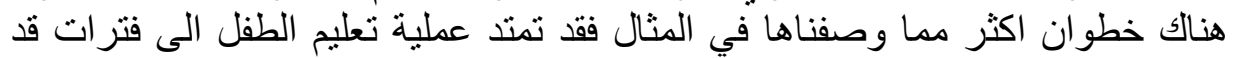

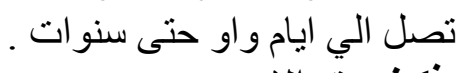

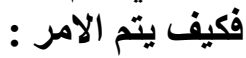

لتطبيق تحليل السلوك التطبيقي بجد تحاول المهارة المعقدة كاستخدام شوكة الطعام

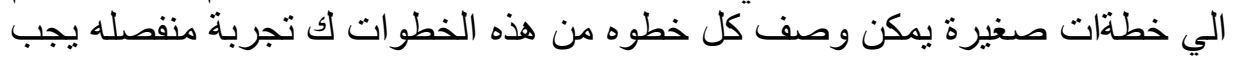

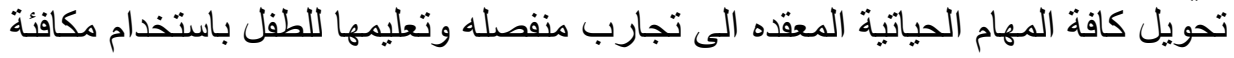

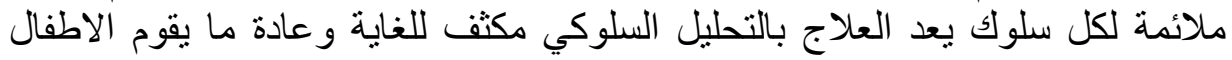

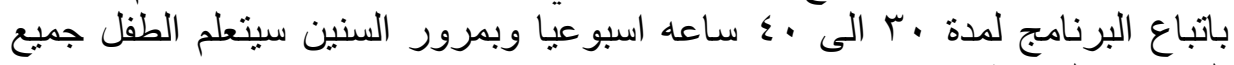
المهار ات الحياتية

هل لله فاعلية ؟ لارب

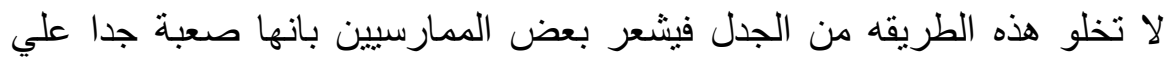

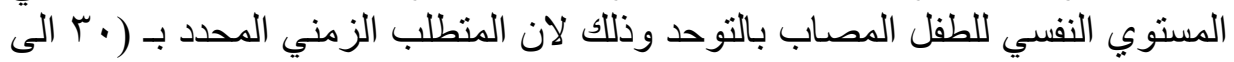

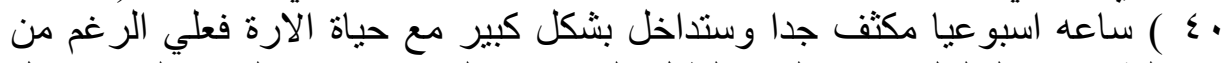

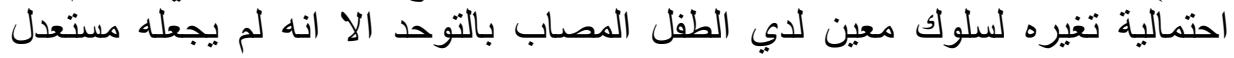

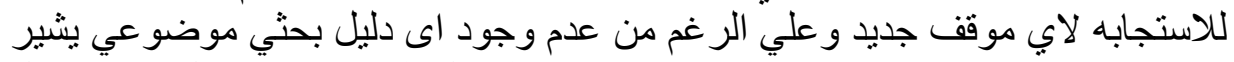

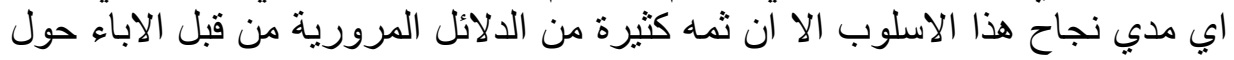

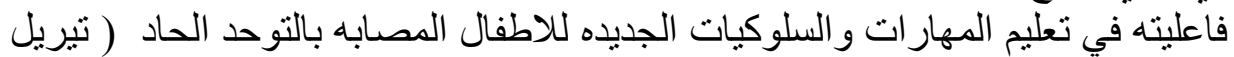
. (VY

teacch برنامج تيتش

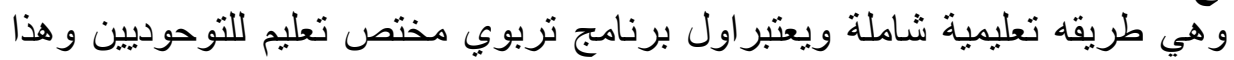

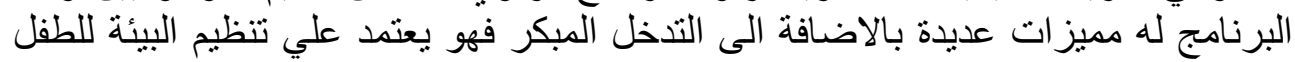

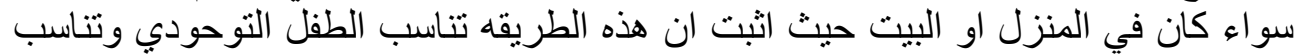


عالمه ومن مز ايا هذا البرنامج انه ينظر للطفل التوحدي علي حده حسب قدر اته الاجتماعية ،

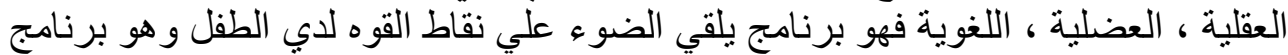

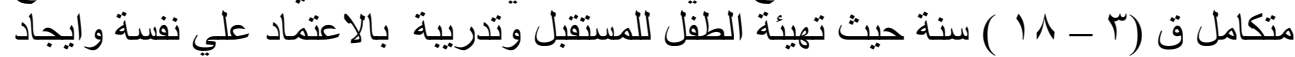

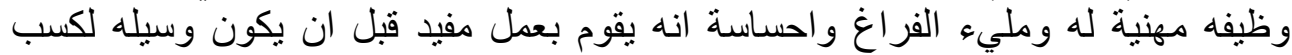

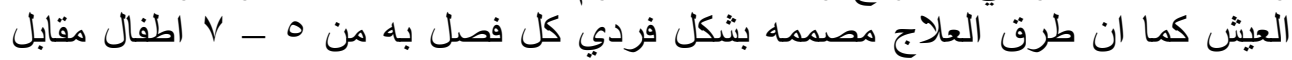

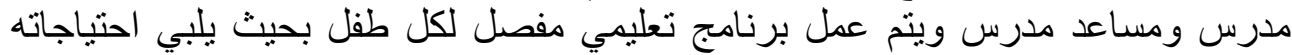

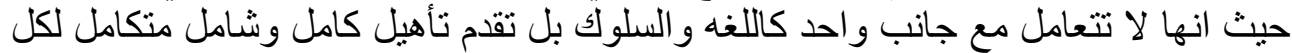

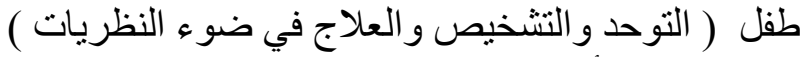
برنامج ليب للأطفال المتوحدين

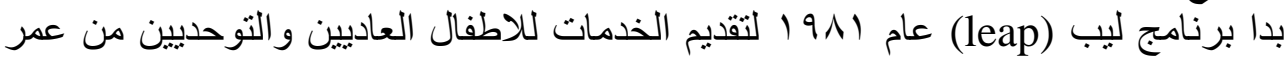

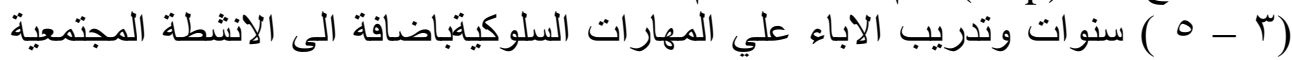

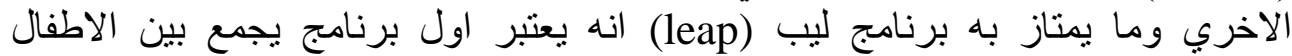

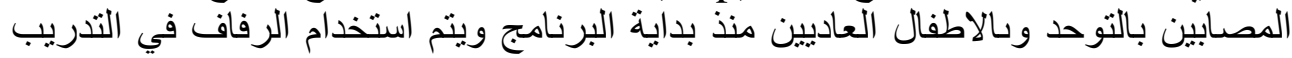

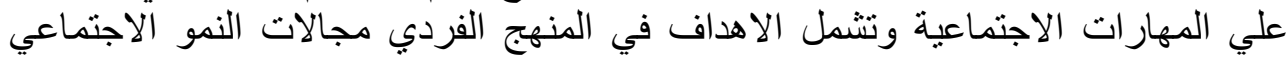

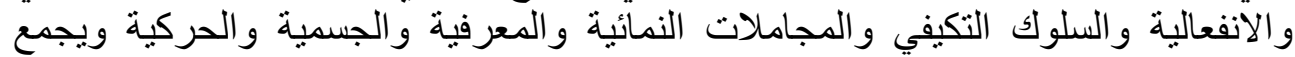
الاسلوب السلوكي مع الممارسات النمائية المناسبة

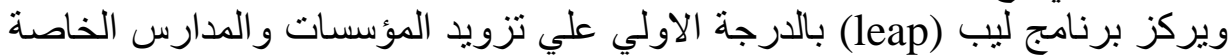

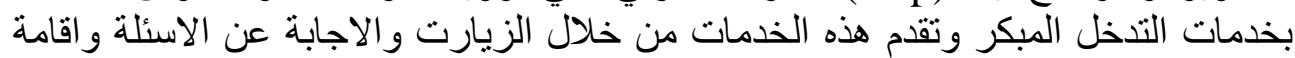

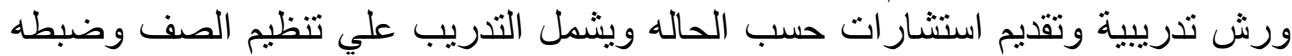

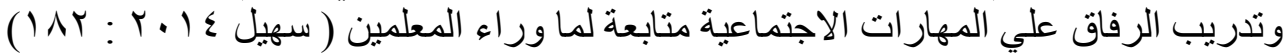

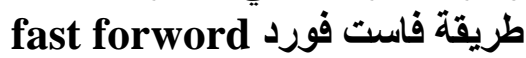

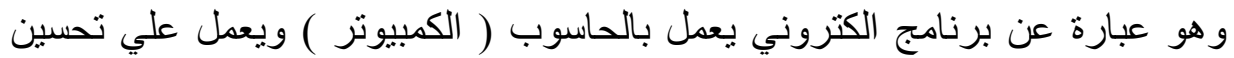

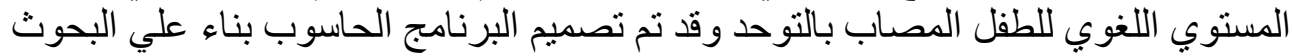

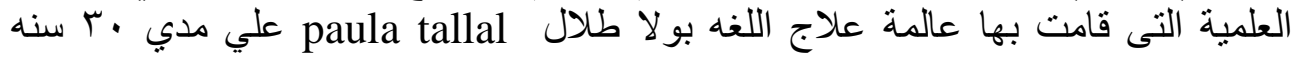

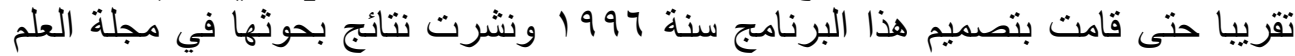

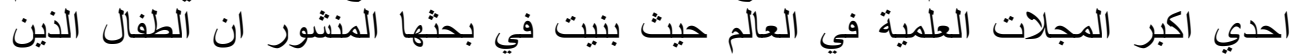

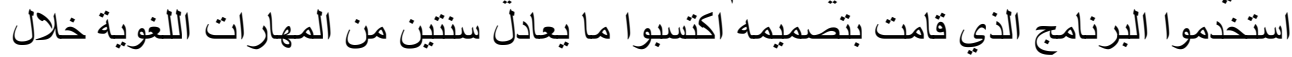

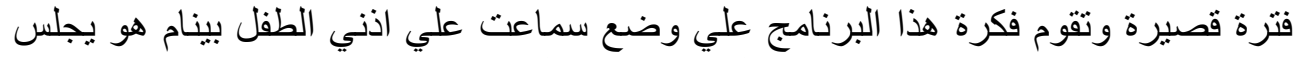

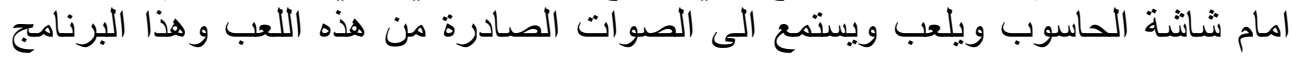

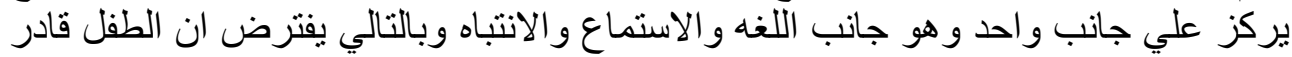

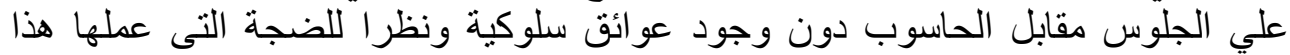

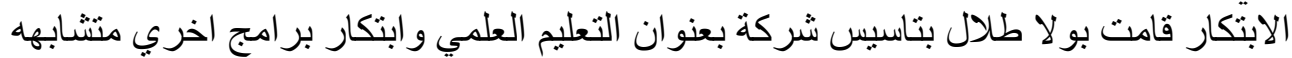


كلها تركز علي تطوير الدهارات اللغويه لاي الاطفال الذين يعانون من مشاكل في النمو لئه

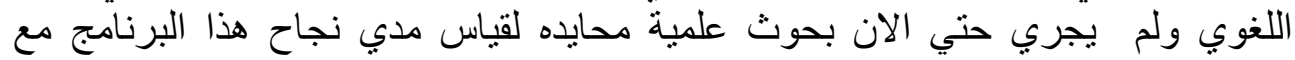

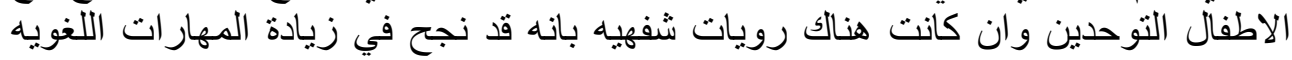

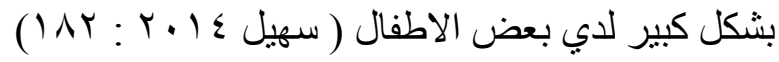
الارشـاد الاسري الاطغي

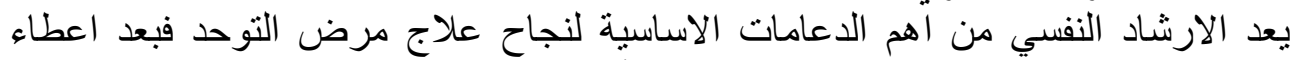

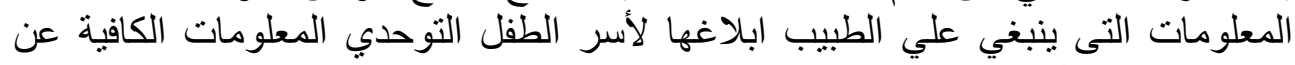

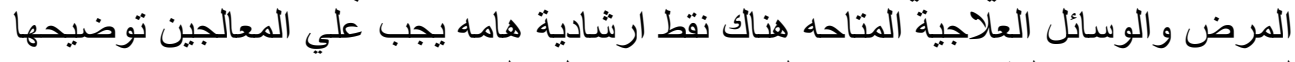

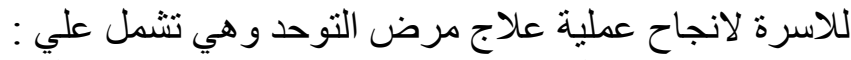

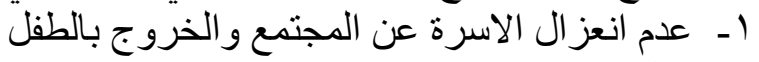

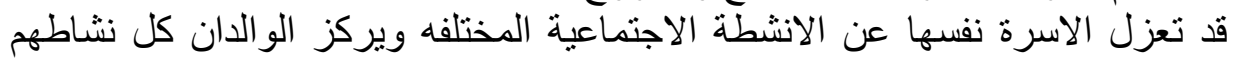

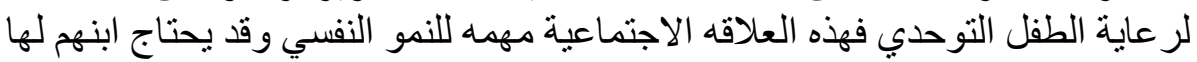

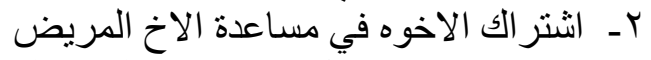
الاخوة سواء كانو اطفال او مر اهقين لايهم تلقائية وبساطة في التعامل قد تكون ذات فائده عظيمة للطفل

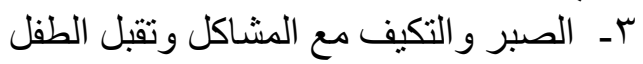
حيث ان تغيير السلوك للطفل التوحدي يحتاج الى اسابيع وشهور لكي يمكن الحصول

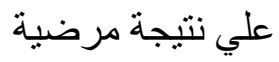
ـ - العلاج النفسي بالاحضان فهو يساعد علي تنمية قدرة الطفل التو اصلية وتفاعلة الاجتماعي

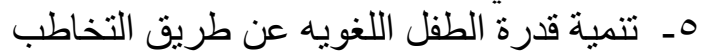

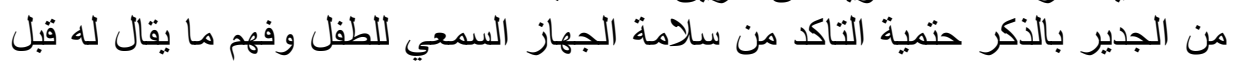

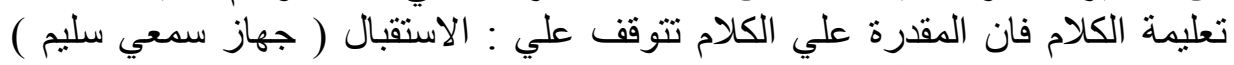

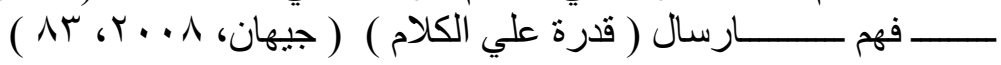
النتائج من خلال سرد العناصر السابقه توصلنا الى ان التوحد اضطر اب نمائي يظهر في الإني

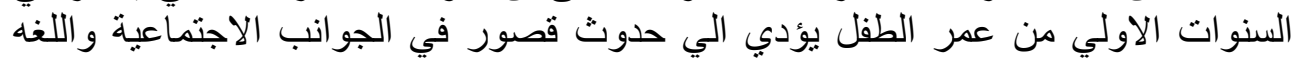

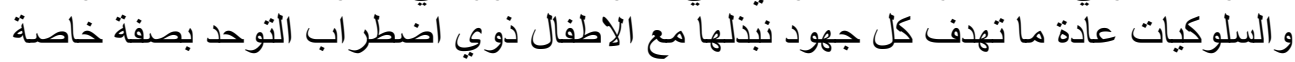

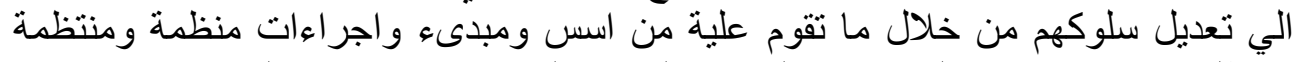

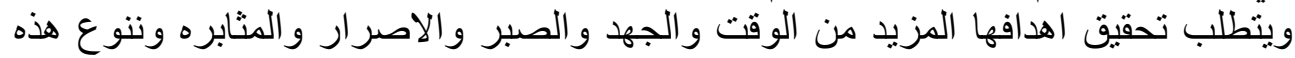

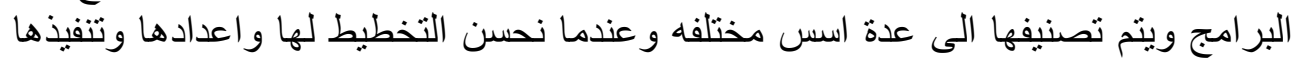
يؤدي الى مخرجات جيده ويعد التنخل المبكر هو ذلك النوع من التذخل بما يتضمنه بخدمات التهات 
مختلفه عديده يتم تقديمها للطفل المعاق خلال السنوات الاولي من عمره و عادة ما يرتبط بها ما يعرف بالخطة الفردية كما ان هنالك العديد من البرامج التدربية التى يتم تقديمها سواء للاطفال ذوى اضطراب التوحد او والديهم وذلك في سبيل تعديل سلوك وتعليم وتدريب هؤلاء الاطفال ومع ان نسبة الثفاء الكلي من المرض صغول صغيرة مقارنة بعدم الثفاء الا انها ليست مستحيله حيث ان الاطفال الذي عمل معهم لو فاس يعد ، ع ساعة تدريب اسبو عيا تحسنوا وحققوا الثفاء وتمكنوا من اللحاق بالمدارس العادية وذلك ما ذكرة في تقريرة عام

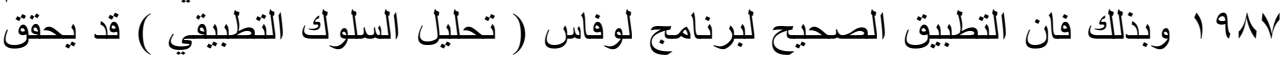

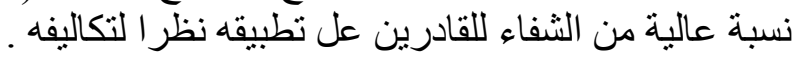
وبرنامج تيتش الذي يتميز بطريقه علمية شامله و لا يتعامل مع جانب و احد فقط ويركز علي نقاط القوه لدي الطفل وطريقة فاس فورت التى لهانجاحات في الجانب اللغوي فكما

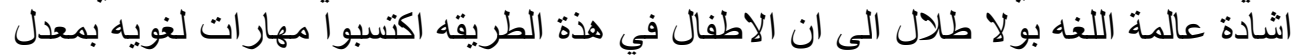
سنين في وقت قصير جدا بالاضافه الى العلاج السلوكي والنفسي والدوائي و الحمية الغذائية

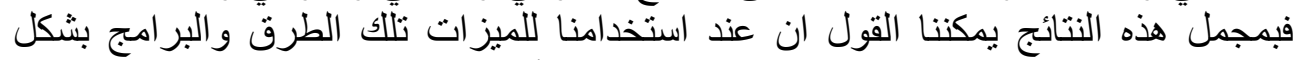
تعاوني بينهم يمكننا الحد من اعر اض هذا المرض ون ونأهيل هؤلاء الاطفال في كافة الجو انب

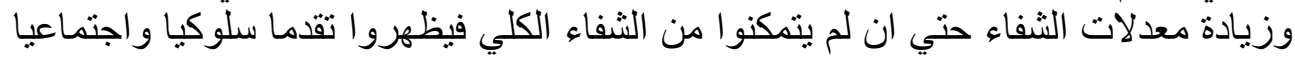

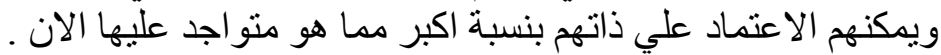

التعقيب والتوصيات

من المتعارف علية او كما سردنا في البدايه ان الاكتشاف المبكر لهذا المرض بعد بعد من افضل السبل لبداية العلاج وتحقيق النتائج المقبوله بشكل اسر ع و افضل ولكن ولكن بعض الإن الاطفال

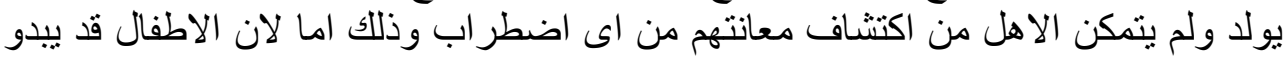
طبيعيين او ان الاهل ليسو علي قدر كافي من المعرفه باعر اض هذا الاضطر اضل هن اب ويبقي السؤال كيف يمكن توعيتهم به و التاكد من هذه التوعية سوف تصل لعد لعد اكبر من الاباء بمختلف الفئات اعتقد ان يمكن فعل ذلك عن طريق الوحدات الخاصة بتطعيمات الطفل في وني سن مبكر حيث يمكن في هذا الوقت اكتثاف القصور اللغوي والسلوكي و الاجتماعي وظهور التهري انخفاض التركيز والانتباه او ظهور اى الاعر اض التى تمكت الاخصنئي او الاكتور المختص من تشخيص هذا الطفل فيتمن بذلك التوصيه بوجود مختص بكل وحدة صحية اة التهية

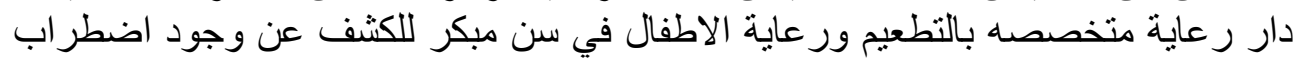

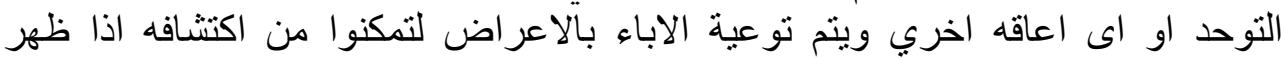

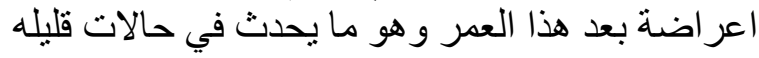
كما ذكرنا يمكننا تطبيق البرنامج العلاجي في الجلسات وفي البيئة الخارجيه كالمنزل

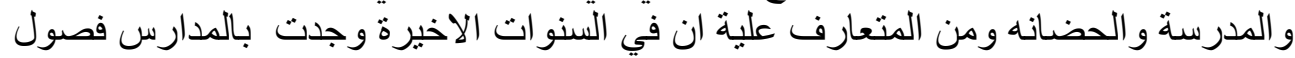

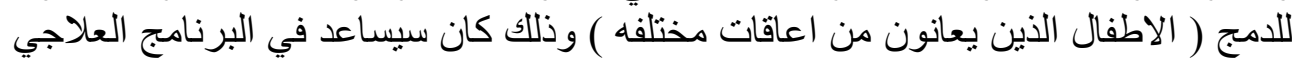


من حيث تغير بيئة تلقي التأهيل و التعميم لتفادي الانتكاسات التى تحدث في البيئة الخارجية التانية

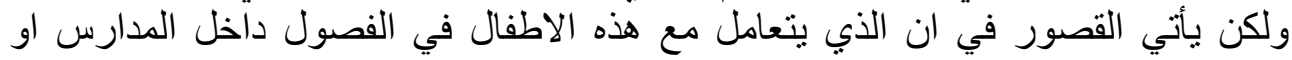

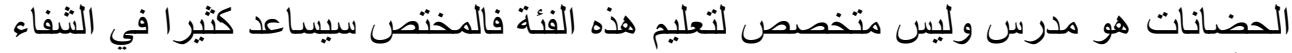

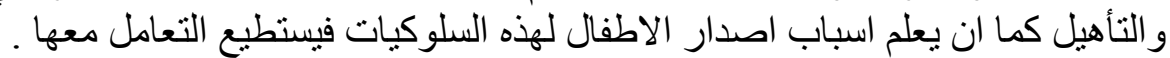

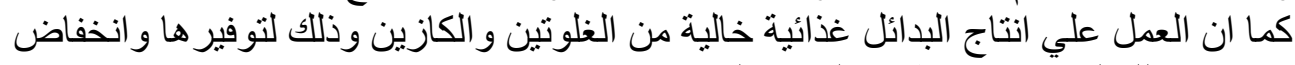

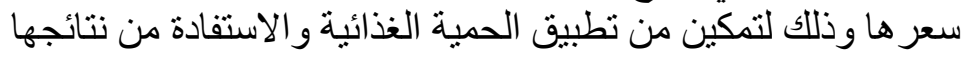

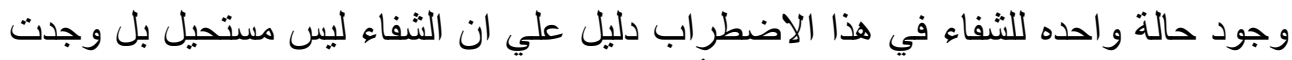

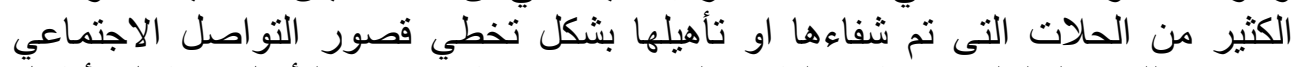

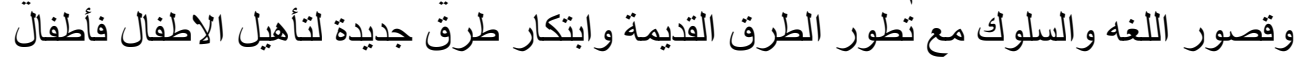

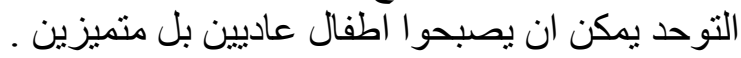

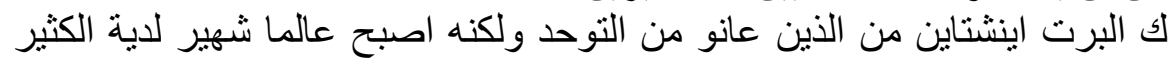

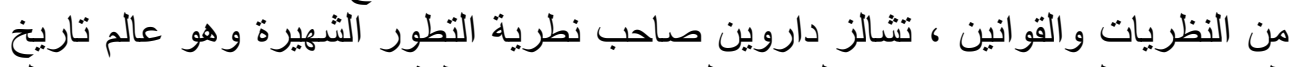

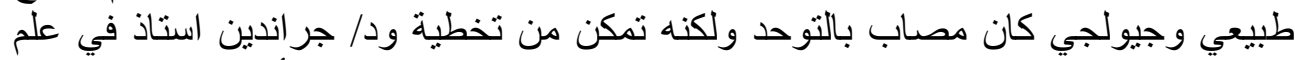

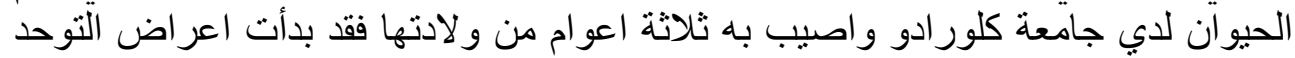

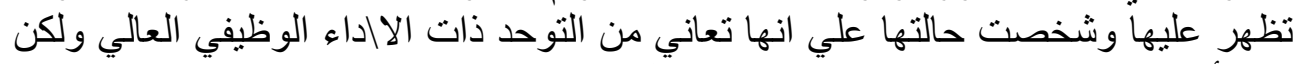

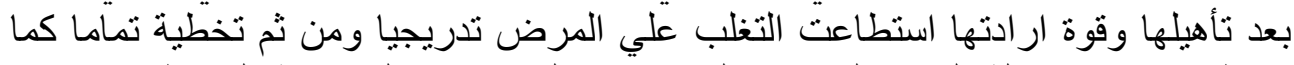

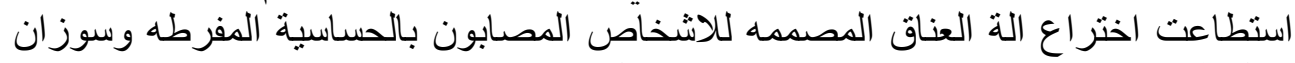
بويل التى ابهرت العالم بصوتها فلا شىء مستحيل لئل العيل

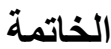

تناولنا في بحثنا طرق العلاج والتأهيل التى قد تساعد الطفل التوحدي علي التأقلم

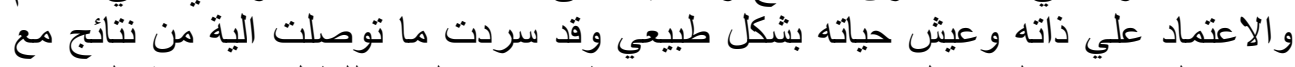

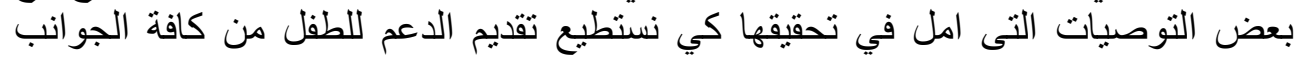

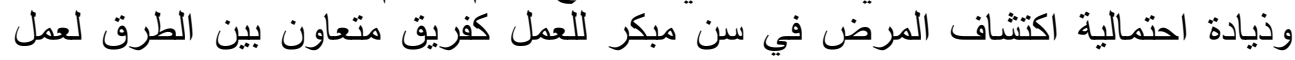
برنامج خاص للطفل واختيار طرق التفكير الابداعي كنمط للحياة 
اسامه فاروق كمال والسيد كمال الشربيني (• (1). التوحد (الاسباب - التشخيص -

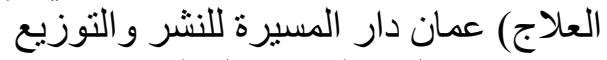

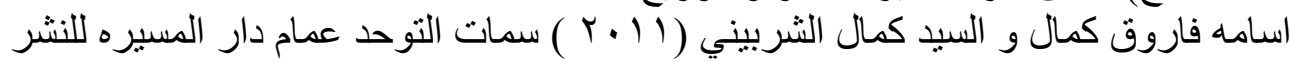

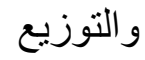

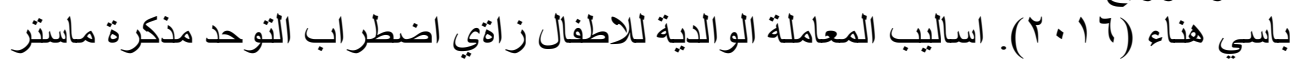

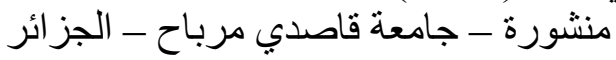

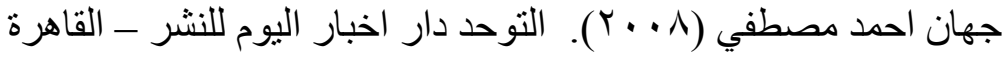

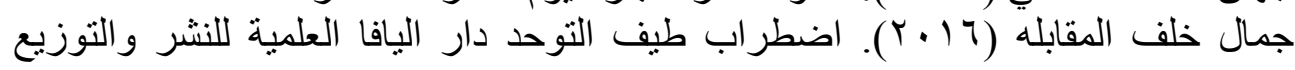

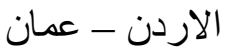

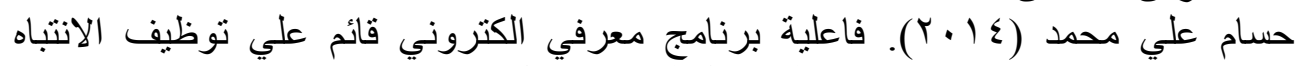

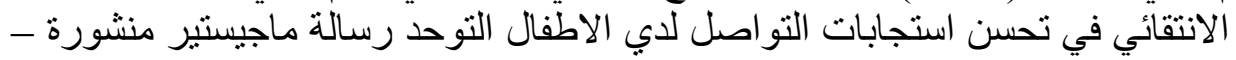

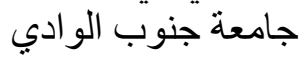

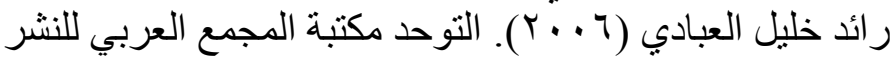

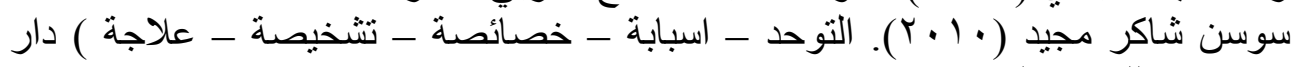

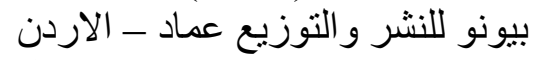

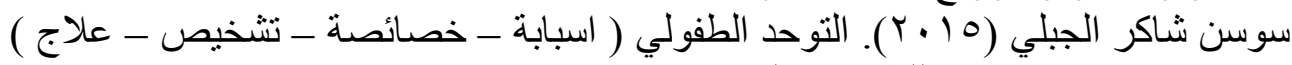

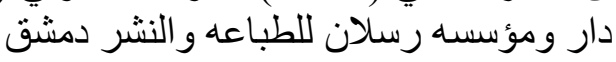

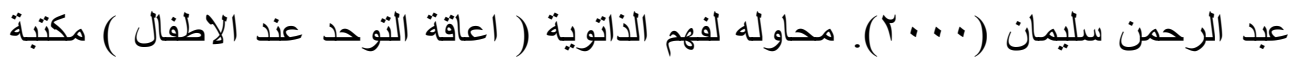

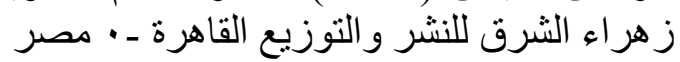

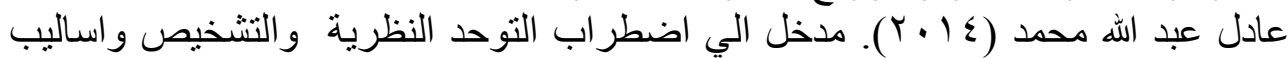

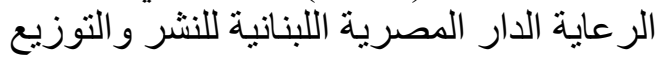

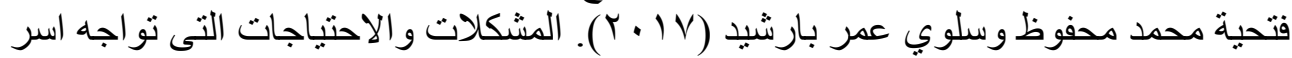

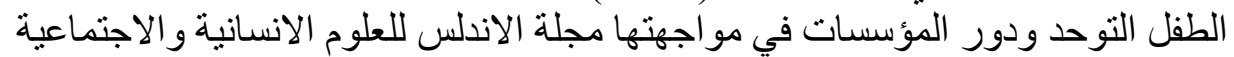

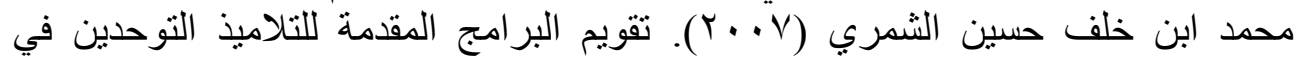

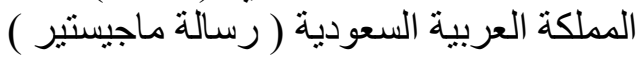

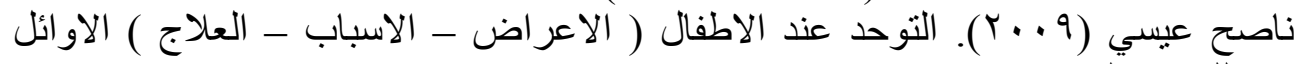

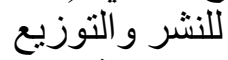

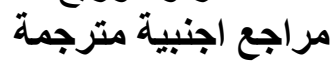

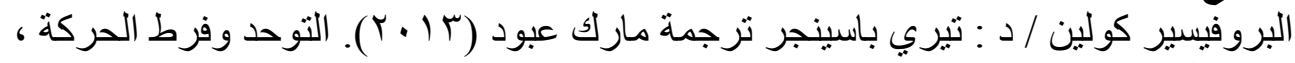

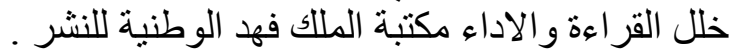

